\title{
El mito de la California del cobre: el impacto del boom minero en el tejido empresarial onubense
}

\author{
- Juan Diego Pérez Cebada \\ Universidad de Huelva \\ - Cinta Concepción García VÁzQuez \\ Universidad de Sevilla
}

\section{Introducción}

En los últimos decenios del siglo XIX la provincia de Huelva experimenta un inicial proceso de industrialización que es especialmente evidente en la propia capital y que está estrechamente ligado a la explotación de sus ricos yacimientos mineros. En esas fechas se extiende el tópico mediático de una provincia dinámica e industriosa que, en realidad, había comenzado a fraguarse en los años cincuenta del siglo XIX, en el entorno del redescubridor de la cuenca onubense, el francés E. Deligny. En efecto, la expresión «California del cobre», atribuida al financiero (y socio del ingeniero francés) M. E. Duclerc ${ }^{1}$ y que anunciaba el potencial industrializador de la minería onubense, va a hacer fortuna. ${ }^{2}$ En los sesenta y setenta varios ingenieros liberales, con I. Gómez Salazar a la cabeza, abordan los diversos efectos de arrastre de la minería lo que les llevaba a considerar que la provincia se iba a convertir en un centro industrial de primer orden. Señala también Gómez Salazar el papel fundamental de una línea ferroviaria que conectara la cuenca con la ciudad de Huelva, como también lo hacen otros informes, como el redactado en 1870 por J. Monasterio y que el propio Deligny, ingeniero ferroviario, había contemplado. ${ }^{3}$ Cuestiones que encuentran eco en la prensa internacional especializada ${ }^{4}$ y que son

1. El Genio de la Libertad, 16 de noviembre de 1855, p. 3.

2. Un par de años después, J. Rieken (1857), p. 49, amigo y colaborador de Deligny, recoge esa expresión, más tarde utilizada también por J. Gonzalo y Tarín (1888), p. 10, que trabajó a su servicio en la Sociedad de Minas de Alosno.

3. Flores (2017), pp. 152-155.

4. La revista La Minería (23 de mayo de 1874, p. 3), dirigida por Gómez Salazar, recoge un artículo del corresponsal de The Mining Journal que habla del «brillante y próspero porvenir» de la provincia. 
abiertamente compartidas por la burguesía de negocios local ${ }^{5}$ y por las más importantes instituciones provinciales. ${ }^{6}$

En realidad, la construcción de mitos con intencionalidad retórica es una constante de la literatura minera. ${ }^{7}$ En Huelva el mito cumplió muy bien su función, ${ }^{8}$ pues sirvió para movilizar a las redes de negocio nacionales y europeas que, como se verá, facilitarán la llegada de una nueva clase empresarial con estrechas vinculaciones con el sector. El principal objetivo de este artículo será analizar la capacidad de esos emprendedores para romper las inercias de la economía preindustrial y, en ese sentido, comprobar si actúan como verdaderos agentes del cambio schumpeterianos. Una línea de trabajo que va a ser abordada a partir de las complejas relaciones a largo plazo entre el empresario, la empresa y su entorno, desde una perspectiva integradora y haciendo especial hincapié en un enfoque socio-cultural. ${ }^{9}$ Para ello, se van a estudiar diez empresas familiares provinciales ${ }^{10}$ en dos períodos, separados por

5. La confianza en los efectos multiplicadores de la minería, el papel vertebrador del ferrocarril y la ideología liberal a ultranza confluyen, por ejemplo, en el empresario local más relevante, G. Sundheim, un self made man cuyo pensamiento económico se resume, según A. Contreras, director de la Revista Minera (RM), así: «... la industria minera exige para su desarrollo una libertad absoluta: la legislación es casi inútil, cuando no perjudicial; todo debe fiarse a la iniciativa individual; el Estado nada tiene que hacer sino ayudar indirectamente, reduciendo los tributos y facilitando los transportes» (RM, 1899, p. 153).

6. Si la Cámara de Comercio Industria y Navegación dirige sus gestiones a «influir en el porvenir de su naciente y progresivo movimiento mercantil e industrial» (La Provincia, 31 de octubre de 1892, s.p.), la otra gran institución económica provincial, la Junta de Obras del Puerto, insistía en la necesidad de invertir en la construcción de una industria manufacturera de escala, aprovechando la mano de obra barata y la proximidad a las materias primas (Archivo del Puerto de Huelva (APH), Leg. 2251, 1912, s.p.).

7. Mainier (2003), p. 12. En ocasiones los empresarios promueven discursos que, como los onubenses, describen un contexto de oportunidades (Carr, 1986) que forma parte de determinados patrones ideológico-culturales. La influencia de estos patrones en la aparición y desarrollo de la empresarialidad en Amit, Glosten y Muller (1993), p. 820. La referencia al mito de California también fue utilizada en 1855 por un periodista alemán al referirse a un distrito minero en la cuenca del Ruhr (Ludwig, 2012, p. 48).

8. Al respecto dice A. M. Bernal (Ferrero, 2000, p. 29): «Entre el mito y la historia, el discurrir de la minería onubense ha sido... uno de los referentes más reiterados — por emblemático - del pasado económico del Sur peninsular». Sobre la inversión extranjera en el sector es significativo el título de un trabajo de A. Broder (2015): «Mitos, ensoñaciones y realidades de El Dorado Minero».

9. Veánse Valdaliso y López (2007), p. 22 y Veciana (1999), pp. 24-26. Más allá del tópico sobre la falta de mentalidad empresarial, la controversia sobre la industrialización y la empresarialidad en Andalucía se inclina cada vez más por estudiar precisamente las condiciones del entorno (Rubio y Garrués, 2017a, p. 795).

10. Se han elegido tanto por su peso en el seno de la vida económico-empresarial como porque forman dinastías de al menos tres generaciones (Landes, 2006, p. 323). El sentido dinástico también se relaciona con una gestión encomendada exclusivamente a miembros del núcleo familiar, tal como lo entiende Casson (1999). Sobre la empresa familiar española pueden consultarse, entre otros, los trabajos de P. Fernández y N. Puig (2004, 2007). Una revisión actualizada sobre el concepto de empresa familiar en F. J. Fernández y F. Gutiérrez (2017). En Huelva, tres trabajos sobre el mundo empresarial son los de Miró (1994), Ferrero (2000) y Pérez (2011). 
CUADRO 1 - Ciclo de negocios de las empresas familiares seleccionadas.

\begin{tabular}{|c|c|c|c|}
\hline \multicolumn{2}{|c|}{$\begin{array}{l}\text { La generación pionera } \\
\qquad(1850 \mathrm{~s}-1900 \mathrm{~s})\end{array}$} & \multicolumn{2}{|c|}{$\begin{array}{l}\text { La consolidación de la empresa familiar } \\
\qquad(1900 s-1936)\end{array}$} \\
\hline $\begin{array}{l}\text { Nombre / razón } \\
\text { social }\end{array}$ & $\begin{array}{l}\text { Actividades } \\
\text { principales }\end{array}$ & $\begin{array}{l}\text { Nombre / razón } \\
\text { social }\end{array}$ & $\begin{array}{l}\text { Actividades } \\
\text { principales }\end{array}$ \\
\hline $\begin{array}{l}\text { SRC Sundheim- } \\
\text { Doetsch }\end{array}$ & $\begin{array}{l}\text { Minería (manganeso, } \\
\text { cobre), banca, } \\
\text { ferrocarriles, } \\
\text { construcción } \\
\text { (mármol), servicio de } \\
\text { aguas, turismo, vinos, } \\
\text { pesca, actividades } \\
\text { inmobiliarias }\end{array}$ & $\begin{array}{l}\text { Justa y Carlos } \\
\text { Sundheim de la } \\
\text { Cueva }\end{array}$ & $\begin{array}{l}\text { Minería, servicio de } \\
\text { aguas }\end{array}$ \\
\hline $\begin{array}{l}\text { Manuel Vázquez } \\
\text { López }\end{array}$ & $\begin{array}{l}\text { Minería (manganeso, } \\
\text { cobre), banca, } \\
\text { electricidad, } \\
\text { construcción, vinos, } \\
\text { actividades } \\
\text { inmobiliarias }\end{array}$ & $\begin{array}{l}\text { SRC Hijos de } \\
\text { Vázquez López }\end{array}$ & $\begin{array}{l}\text { Banca, minas, } \\
\text { actividades } \\
\text { inmobiliarias, vidrios } \\
\text { y derivados, servicio } \\
\text { de aguas }\end{array}$ \\
\hline $\begin{array}{l}\text { José y Juan Tejero } \\
\text { Hidalgo }\end{array}$ & $\begin{array}{l}\text { Minería (manganeso, } \\
\text { servicios de } \\
\text { intermediación e } \\
\text { inversiones directas), } \\
\text { arrendatario de } \\
\text { impuestos }\end{array}$ & $\begin{array}{l}\text { José Tejero } \\
\text { González Vizcaíno }\end{array}$ & $\begin{array}{l}\text { Pesca, minas } \\
\text { (servicios de } \\
\text { intermediación) }\end{array}$ \\
\hline $\begin{array}{l}\text { SRC Francisco } \\
\text { Jiménez y Cía }\end{array}$ & $\begin{array}{l}\text { Vinos, banca, minería } \\
\text { (manganeso, hierro), } \\
\text { construcción, gas } \\
\text { y electricidad, } \\
\text { empresario teatral, } \\
\text { actividades } \\
\text { inmobiliarias }\end{array}$ & $\begin{array}{l}\text { Eustaquio Jiménez } \\
\text { Mantecón } \\
\text { Manuel e Ignacio } \\
\text { Jiménez Jerez }\end{array}$ & $\begin{array}{l}\text { Vinos, } \\
\text { construcción }\end{array}$ \\
\hline $\begin{array}{l}\text { SRC Thomas } \\
\text { Morrison y Cía } \\
(1891)\end{array}$ & $\begin{array}{l}\text { Minería (cobre, } \\
\text { azufre), fundición } \\
\text { y comercialización } \\
\text { de metales, banca, } \\
\text { explosivos, seguros }\end{array}$ & $\begin{array}{l}\text { SRC Morrison } \\
\text { y Haselden }\end{array}$ & $\begin{array}{l}\text { Comercialización de } \\
\text { metales, } \\
\text { consignatarios de } \\
\text { buques, seguros }\end{array}$ \\
\hline Antonio Mora García & $\begin{array}{l}\text { Minería, ferrocarril, } \\
\text { servicio de aguas, } \\
\text { arrendatario de } \\
\text { impuestos, agricultura }\end{array}$ & $\begin{array}{l}\text { Hijos de Antonio } \\
\text { Mora } \\
\text { Antonio de Mora } \\
\text { Claros }\end{array}$ & $\begin{array}{l}\text { Servicio de aguas } \\
\text { electricidad, gas, } \\
\text { agricultura, minas } \\
\text { (servicios de } \\
\text { intermediación), } \\
\text { prensa, arrendatario } \\
\text { de impuestos }\end{array}$ \\
\hline Matías López Oller & $\begin{array}{l}\text { Fundición, } \\
\text { comercialización } \\
\text { metales, vinos, pesca }\end{array}$ & $\begin{array}{l}\text { Joaquín López } \\
\text { Gómez } \\
\text { Antonio López } \\
\text { Gómez }\end{array}$ & $\begin{array}{l}\text { Fundición, } \\
\text { vinos }\end{array}$ \\
\hline
\end{tabular}




\begin{tabular}{llll}
\hline \multicolumn{1}{c}{$\begin{array}{c}\text { La generación pionera } \\
\text { (1850s-1900s) }\end{array}$} & \multicolumn{1}{c}{$\begin{array}{c}\text { La consolidación de la empresa familiar } \\
\text { (1900s-1936) }\end{array}$} \\
\hline $\begin{array}{l}\text { Eduardo Díaz } \\
\text { Gómez de Cádiz }\end{array}$ & $\begin{array}{l}\text { Minería, vinos, } \\
\text { actividades } \\
\text { inmobiliarias }\end{array}$ & $\begin{array}{l}\text { Hijos de Eduardo } \\
\text { Díaz }\end{array}$ & $\begin{array}{l}\text { Importación- } \\
\text { exportación de } \\
\text { maderas, agricultura, } \\
\text { actividades } \\
\text { inmobiliarias }\end{array}$ \\
\hline $\begin{array}{l}\text { Miguel Sánchez-Dalp } \\
\text { y Guzmán }\end{array}$ & Minería, agricultura & $\begin{array}{l}\text { Bernabé, Francisco } \\
\text { Javier y Miguel } \\
\text { Sánchez Dalp }\end{array}$ & Agricultura, minería \\
\hline SRC Clauss-Wetzig & Minería (directivo), \\
& $\begin{array}{l}\text { química (fábrica de } \\
\text { guano), vinos }\end{array}$ & $\begin{array}{l}\text { SRC Wetzig- } \\
\text { Weickert }\end{array}$ & $\begin{array}{l}\text { Química (fábrica de } \\
\text { guano) }\end{array}$ \\
\hline
\end{tabular}

la primera década del siglo Xx, prestando atención al ciclo de negocios de estos emprendedores (resumido en el cuadro 1), en los dos primeros epígrafes, y a su organización institucional, ${ }^{11}$ en el tercer epígrafe. Las consecuencias de la fuerte dependencia del sector minero, protagonista de la globalización y dependiente de la gran empresa, ${ }^{12}$ son examinadas en el último epígrafe a partir de una serie de reflexiones sobre las dinámicas relaciones entre disponibilidad de recursos naturales, organización institucional y tejido productivo en el espacio provincial. ${ }^{13}$

\section{La generación pionera}

\section{La gran minería: el círculo de Deligny}

Se considera la expedición de Ernesto Deligny a Huelva en 1853, que él mismo describió con detalle diez años después, ${ }^{14}$ como el punto de partida del

11. Partiendo de la investigación sobre las cámaras de comercio provinciales, especialmente la de la capital, la más importante de la amplia red de instituciones formales e informales en torno a las que se organizaron estos emprendedores, la falta de arraigo y la reducción de costes de transacción en entornos empresariales personalistas animan la organización de estas redes empresariales (Granovetter, 1992; Casson, 2010). En Andalucía pueden destacarse los trabajos de Garrués y Rubio (2013), Garrués, Rubio y Hernández (2013), Rubio (2014) y Rubio y Garrués (2017a, 2017b).

12. Véase Sánchez (2011, p. 42). El interés de las nuevas investigaciones sobre la relación entre empresarialidad y procesos globalizadores en Wadhwani y Lubisnky (2017), p. 775.

13. En Andalucía, la cuestión de la dotación de recursos se ha revelado desde hace tiempo como un aspecto clave de la industrialización y la empresarialidad (Parejo, 2011, p. 13; Garrués, Rubio y Hernández, 2013, p. 110). La unidad territorial provincial elegida deriva del mismo mito de la California del cobre y va a ser luego promovida por las autoridades mineras que se refieren indistintamente al distrito minero de Huelva o de Riotinto. Sobre el debate en torno a la unidad de análisis en la historia industrial, véase, por ejemplo, Parejo (2006).

14. RM (1863, n. ${ }^{\circ} 14$, pp. 111-121; 158-165; 182-189; 208-220). 
boom minero en la cuenca. Deligny recorrió la cuenca como representante de un grupo de capitalistas franceses encabezados por el duque de Glucksberg, ${ }^{15}$ registrando minas en la zona de Alosno-Calañas y en el Alentejo (donde funda la sociedad La Sabina) y participando, como gestor de varias compañías, en la explotación de esos yacimientos. Sin embargo, entre 1866 y 1892 una gran compañía inglesa, Tharsis Sulphur and Copper Company (TSCCL), adquiere todas esas minas. ${ }^{16}$ De manera que Deligny se convierte en un perfecto ejemplo de los pionniers malhereux franceses que van a abrir el camino al gran capital inglés. ${ }^{17}$ Pero Deligny ejerce, también, una directa y menos conocida influencia en la conformación de la trama empresarial provincial, ${ }^{18}$ conectando e impulsando a representantes cualificados de las tres redes nacionales que van a nutrir al empresariado local: la inglesa, la alemana y la española.

En el caso británico es interesante resaltar la figura de Henry Frederick Christopher Haselden, un ingeniero civil que, como el mismo Deligny, estuvo inicialmente relacionado con proyectos ferroviarios en Europa y que en 1853 colabora con él en diversos registros de minas de hierro onubenses y va a formar parte de la terna de propietarios, con Gluckberg y Gosse, de la segunda compañía que explotó las minas de Tharsis. Esta familia, en realidad, podía presumir de una contrastada experiencia en el gran negocio minero europeo. ${ }^{19}$ En España, a la vez que irrumpía en Huelva, va a promover, con el concurso financiero de importantes hombres de negocios franceses como el propio Glucksberg o los Pereire, una sociedad (H. Haselden y Compañía) para explotar el mercurio de Almadén al mismo tiempo que se introduce en la minería sevillana del carbón con la Compañía Minera y de Fundiciones de San Fernando. También va a participar activamente en el sector gasístico, dirigiendo las compañías del gas de Madrid y Sevilla desde los años cincuenta. ${ }^{20} \mathrm{~A}$ su muerte, acaecida en esta última ciudad en 1867, sus dos hijos, Eugene y Arthur, continúan los negocios mineros del padre, aunque lejos de Huelva, en las minas de plomo del Centenillo, en Jaén. Será la tercera generación la que se instale de nuevo en Huelva después de la Primera Guerra Mundial, como luego se comprobará.

Jorge Rieken y Gerdes es un temprano representante de la pequeña, pero selecta, colonia alemana de Huelva. Este ingeniero de minas llegó a la provincia en los años cincuenta procedente de Santander. ${ }^{21}$ Aquí, a la vez que es-

15. El auténtico «redescubridor» de las minas para Broder (2015), p. 75.

16. Checkland (1967, capítulo 6); Chastagnaret (2000), pp. 384-389, Broder (pp. 75-91).

17. Chastagnaret (2000), pp. 385.

18. Aunque curiosamente él mismo no fundara ninguna dinastía empresarial.

19. Haselden dirigió en los años cuarenta las minas alemanas de carbón y zinc de Ischeweiler, el gran proyecto franco-belga-alemán de los hermanos Laveissière (Cameron, 1961, p. 376).

20. Fomento (31 de agosto de 1853, pp. 15-16); Madrid (2007, p. 119).

21. Boletín oficial de la Provincia de Santander, $n .^{\circ} 8$ (8 de junio de 1857). 
cribe un par de obras sobre la cuenca que lo convierten en un respetado especialista (Rieken, 1857; 1860), se va a labrar una merecida fama de inquieto emprendedor minero. En la primera década del boom ejerce como director de la compañía Turdetana, relacionada con la familia de empresarios francesa Grimaldi. En los años ochenta se va a desempeñar como arrendador de minas propias a compañías extranjeras como The Bede Metal Company $(\mathrm{Ca}-$ bezas de Pasto y Herrerías) y The London Agency Limited (Sierrecilla y Segunda Manolita). Amigo personal de Deligny, según afirma este mismo en sus «Apuntes», participa con diversos cometidos desde los años setenta en el coto minero de Lagunazo que aquel dirigía. Al final de su vida también invierte en el servicio de aguas de la capital, haciéndose de hecho con la concesión que hasta entonces poseía su concuñado, Guillermo Sundheim. ${ }^{22}$

Las primeras investigaciones de Deligny desataron una primera fiebre minera que tuvo entre los españoles un importante componente especulativo: ${ }^{23}$ para algunos de ellos, sin embargo, la proximidad a Deligny fue el punto de partida de una sólida carrera empresarial. Entre ellos cabe destacar a Eduardo Díaz Gómez de Cádiz. Forma parte de una familia de la burguesía de negocios malagueña entroncada con comerciantes europeos que en los años cincuenta ostenta la representación consular de los países escandinavos y de Holanda en Huelva. ${ }^{24}$ E. Díaz se encuentra ya en 1860 entre los socios fundadores de La Sabina; una década más tarde registra varias de las minas de Alosno que luego formarán el coto minero de Lagunazo y negocia, en nombre de Deligny o del duque de Glucksberg, y en ocasiones con el concurso de Rieken, las escrituras de los restantes yacimientos del ingeniero francés. Se convierte, así, en el hombre de confianza de Deligny en Huelva, a quien presta valiosos servicios y con quien comparte también aventuras empresariales, como la participación en el accionariado de la mina Sotiel Coronada y en el de la Compañía de Minas de Alosno. Este empresario también está presente en el dinámico sector vitivinícola onubense desde los años setenta y en los noventa interviene activamente en el sector inmobiliario de la capital, construyendo diversos edificios destinados a habitación de obreros. ${ }^{25}$

Deligny encontró en estas tierras un abierto apoyo de los profesionales, especialmente de ingenieros de minas que trabajaban en Riotinto, como Miguel Sánchez Dalp y Guzmán, a la sazón director facultativo de ese establecimiento. Este ingeniero, que forma parte de una familia de abolengo minero

22. Gaceta de los Caminos de Hierro (11 de octubre de 1857, p. 5). Archivo Histórico Provincial de Huelva (AHPH) Protocolos Notariales (PN) (4882, doc. 129; 4887, doc. 54; 4890, doc. $42 ; 4962$, doc. 24$)$.

23. Chastagnaret (2000), p. 308.

24. Gaceta de Madrid (19 de noviembre de 1858, p. 1; 8 de diciembre de 1858, p. 1; 19 de diciembre de 1858 , p. 1).

25. AHPH (PN. 4959, doc. 349; 4885, doc. 105; 4894, doc. 7; 4895, doc. 231; 4863, doc. 78); Revista de España (1874, vol. 36, p. 195); La Provincia (22 de octubre de 1893, p. 1). 
vinculada a Almadén, ${ }^{26}$ va a asentarse en Aracena, ciudad de la cual sería alcalde en los años sesenta, gracias a su matrimonio con María de los Santos Calonge, perteneciente a una familia de grandes propietarios serranos. Hombre de inquietudes culturales, además de su trabajo en Riotinto y de las valiosas investigaciones en los cincuenta en la zona de Tharsis, elogiadas en la prensa madrileña, ${ }^{27}$ registrará desde 1.855 minas, dirigirá la explotación del yacimiento de El Carpio en los sesenta, ${ }^{28}$ participará como socio fundador en la sociedad La Sabina y, más adelante, se hará con la propiedad del 4\% de Sotiel Coronada, lo que le causará problemas con Eduardo Díaz. ${ }^{29}$

\section{La pequeña minería: el boom del manganeso}

A pesar del hecho de que la provincia de Huelva se convierte a principios de la década de los ochenta del siglo XIX en la mayor productora mundial de manganeso, las grandes compañías mineras apenas tuvieron interés en su explotación. Sus criaderos irregulares y de pequeñas dimensiones, las dificultades técnicas que presentaban estos yacimientos y su estrecha dependencia de los mercados internacionales explican que en este tipo de minería se especializara el empresariado nativo, tal como ocurre en otras cuencas. ${ }^{30}$ Los más destacados mineros del ramo, que en el quinquenio final del siglo XIX alcanza las más altas cotas de producción, son tres figuras capitales del empresariado onubense: la sociedad Sundheim-Doetsch, Manuel Vázquez López y la familia Tejero.

$\mathrm{Si}$, como Gonzalo y Tarín afirmaba, ${ }^{31}$ el manganeso hizo que el capital internacional pusiera sus ojos en Huelva, probablemente fueron los alemanes los que iniciaron los trabajos ${ }^{32}$ de la mano de la firma Nottebohm Brothers, agentes de los Rothschild en Amberes: primero J. Rieken, como se ha visto, y después G. Sundheim (concuñado del anterior) y E. Doetsch, que se convertirá con el tiempo en Deputy Chairman de Rio-Tinto Company Limited (RTLC), explotan yacimientos de este mineral a través de la compañía del mismo nombre que fundan en 1865; de hecho, son los introductores del vapor en este ramo minero. ${ }^{33} \mathrm{G}$. Sundheim va a ser considerado, dentro y fuera de Huelva, como el auténtico modernizador de la economía de la provincia,

26. Un pariente suyo, Bernabé Sánchez Dalp López fue director general de Minas a mediados del siglo XIX (Gómez-Alba, 2010, p. 27). En 1799 un Manuel Sánchez Dalp es tesorero en Almadén, donde después vivirán sus hermanas (Gaceta de Madrid, 19 de julio de 1799, p. 653).

27. La Nación (1 de enero de 1856, p. 3).

28. RM (1863, pp. 215-216).

29. AHPH. Jefatura Provincial de Minas (JPM) (búsqueda: Sánchez Dalp); PN (4894, doc. 7)

30. RM (1904, p. 568); Ferrero (2000), p. 100

31. Memorias del IGME (MI) (1888), p. 543.

32. Tal como el geólogo Carlos Doetsch Kalt con conocimiento de causa (es sobrino de Enrique Doetsch y yerno de Guillermo Sundheim) defendía (RM, 1902, p. 39).

33. Ferrero (2000), p. 183. 
aunque solo fuera por su participación en los dos grandes proyectos iniciales en los que participó: la llegada de RTCL y la doble conexión ferroviaria de la ciudad con Sevilla y con Extremadura en los primeros años ochenta. Pero, además, no va a escapar a su interés ninguno de los sectores en auge en la provincia: desde el negocio vinatero (produce vinos de marca Río Tinto), al inmobiliario (llegó a acumular un enorme patrimonio rústico y urbano) o al turístico (fue promotor de los baños en Punta Umbría y construyó el lujoso Hotel Colón, el espacio de sociabilidad por antonomasia de la élite local) pasando por el sector pesquero (socio de la compañía La Atlántica) o el bancario. Sin embargo, la pesada carga financiera de alguno de sus negocios, como el ferroviario, y los problemas de liquidez en sus últimos años, van a provocar un fuerte endeudamiento que llevará al empresario a la ruina: cuando muere en 1903, de hecho, sus hijos renunciarán a la herencia. ${ }^{34}$

Manuel Vázquez López fue el empresario de origen onubense más destacado de su generación. De brillante carrera política, fue miembro fundador y presidente de las dos instituciones económicas claves en la provincia, la Cámara de Comercio y la Junta de Obras del Puerto. Comenzó tempranamente, a finales de los años cincuenta, en el negocio del manganeso, pero la volatilidad del sector lo hizo inclinarse por las minas de cobre, especialmente en el criadero de La Joya, que arrienda entre 1879 y 1895 a The Bede Metal. Su perfil empresarial es muy diversificado, pues, junto a las actividades agrarias (relacionadas con la producción de vinos de su bodega), o su intervención momentánea en el negocio eléctrico, se especializa en el negocio bancario (hasta convertirse en el primer banquero de la ciudad) y desde los préstamos hipotecarios va a desembocar en el mercado inmobiliario, el negocio que a finales de su carrera tiene, desde el punto de vista de la carga fiscal, más peso entre sus bienes. ${ }^{35}$

La familia Tejero representa muy bien las oportunidades y desafíos que para el minero local tuvo el manganeso. Aunque es el padre (Bartolomé Tejero) el que explota los primeros yacimientos en su pueblo natal, Calañas, en los años sesenta, van a ser sus hijos Juan (secretario del Ayuntamiento y alcalde más tarde) y José Tejero Hidalgo (médico) quienes alcancen un efímero éxito al lograr la tercera posición en el ranking de exportadores provinciales (y nacionales) en torno al cambio de siglo. Sus contactos internacionales (Juan Tejero fue el primero que exportó manganeso en Huelva) y las fuertes oscilaciones del mercado llevaron al clan familiar a especializarse en la representación de empresas como Sociedad Anónima Peninsular, Companhia Portuguesa das Minas de Huelva o Central Copper Mines of Spain. ${ }^{36}$

34. Pérez (2011), pp. 302-307.

35. Ibid. (pp. 248-253).

36. $R M(1899$, p. 82); AHPH PN (4963, doc. 79: 4938, doc. 549); EM (1890-1891, pp. 127 y 131); La Provincia (2 de enero de 1900, s.p.); Mojarro (2007, p. 76). 


\section{Los efectos de arrastre: química, fundiciones y distribución}

La capacidad del sector extractivo para generar valor en otras actividades de la cadena productiva o en otros sectores ha sido motivo de intensa controversia ${ }^{37}$ Aunque la utilización del azufre como materia prima para la floreciente industria química fue entendida pronto por las grandes empresas radicadas en la cuenca (RTCL construye su gran planta en 1905), impulsando ese sector en Andalucía, ${ }^{38}$ también hubo una empresa local que encontró un nicho de mercado en este sector tempranamente. «Dos alemanes verdaderamente emprendedores» ${ }^{39} \mathrm{~B}$. Wetzig, ingeniero químico formado en las prestigiosas universidades de Friburgo y Heidelberg y director de las minas de San Telmo, y su socio G. Weickert (aunque este se incorporará más tarde a la sociedad), van a levantar en los años noventa del siglo XIX una fábrica de abonos orgánicos que, a principios de siglo, se especializa en superfosfatos. En esas fechas se estimaba que su capacidad productiva podría alcanzar las $15.000 \mathrm{Tm}$ anuales, lo que convertía a esa empresa en una de las cinco más importantes de España. ${ }^{40}$

Como se verá, la verticalización de las actividades metalúrgicas de las grandes empresas del cobre no dejó espacio a la competencia en la provincia de Huelva. En cambio, sí surgieron algunas fundiciones relacionadas con la metalurgia del hierro, a pesar de la crisis a escala regional del sector. ${ }^{41} \mathrm{La}$ fundición pionera en este caso fue fundada en 1880 por el sevillano Matías López Oller, un empresario autodidacta dotado de gran habilidad manual. Sus productos, orientados sobre todo al sector agrícola (su especialidad eran las prensas para aceites y vinos), se van a extender por Andalucía y Extremadura. Su fábrica llegó ser considerada por el rey Alfonso XIII, de visita en Huelva, como el gran símbolo de modernización de la ciudad. ${ }^{42}$

Su rival en Huelva, la casa Thomas Morrison and Company, sí que, en cambio, está vinculada a las grandes empresas mineras, bien porque el primer representante de la familia, D. Morrison, fue Assistant Commercial Manager de TSCCL, como porque mantienen estrechas relaciones económicas con RTCL. ${ }^{43}$ El inicial negocio de fundición, sin embargo, fue perdiendo protagonismo a favor del desarrollo de una red nacional de distribución de productos

37. Sánchez (2011), pp. 50-51.

38. Bernal, Martínez y Florencio (2010), p. 217.

39. El Liberal (4 de noviembre de 1899, s.p.).

40. El Adelanto (20 de febrero de 1908, s.p.); Pérez (2011), p. 370.

41. Bernal, Martínez y Florencio (2010), pp. 214-215.

42. Pérez (2011), pp. 325-329.

43. Repositorio Arias Montano, disponible en línea: www. http://rabida.uhu.es/dspace/ handle/10272/5493. Report by the Directors of the TSCCL (1875, p. 4); Delgado et al. (2011, p. 316). 
metalúrgicos, que también ejerce como casa de banca. ${ }^{44}$ Esa red se apoya en cinco sucursales en territorio nacional, dependientes de la de Londres, en un completo catálogo de veinte páginas y en un cuidado servicio de venta al cliente. Su fiabilidad les permite ser considerados como consultores expertos en el mercado de hierro por revistas especializadas europeas. ${ }^{45}$

\section{Las redes urbanas y el sector vitivinícola}

Los servicios públicos ligados a la expansión urbana ofrecieron grandes oportunidades de negocio a los empresarios andaluces, ${ }^{46}$ como la familia Mora. Se trata de una familia de propietarios de La Ribera, en las inmediaciones de la ciudad, que participan tempranamente en la fiebre minera, seguramente por iniciativa de Joaquín Mora García, interventor de las minas de la provincia, pero también en el mercado hipotecario local ${ }^{47}$ De entre ellos destaca la figura de Antonio Mora García, fiel de consumos de la ciudad, que combinará su carrera empresarial con la política, militando en las filas del Partido Conservador desde el que alcanzará la vicepresidencia de la Autoridad Portuaria y del Ateneo. Interesado tempranamente por el negocio ferroviario, ${ }^{48}$ en 1875 consigue licencia del Ayuntamiento para la traída de aguas desde su finca en La Ribera, y en 1883 ya ha adquirido las tuberías a una compañía de Glasgow. Después de una reñida pugna con otras empresas locales, promovidas por Sundheim y Vázquez López, en la que se airearon sus manejos políticos, Antonio Mora García logra hacerse con el control de una de las compañías de abastecimiento de aguas, que cederá a su hijo Andrés de Mora. ${ }^{49}$ Otro de sus hijos, Antonio de Mora Claros, terminará controlando también la compañía de electricidad, como luego se comprobará.

Representante de The Huelva Gas and Electricity Co. Lted, la compañía inglesa que había gestionado esos servicios hasta la irrupción de Mora Claros, será Francisco Jiménez y Jiménez, alcalde y concejal en los setenta de la capital. Se trata de la figura más destacada del clan de Cameros, compuesto por varias familias de origen riojano instaladas en el condado desde la segunda mitad del siglo XVIII. Aunque su rango de intereses comerciales es muy di-

44. El Radical (19 de febrero de 1908, s.p.).

45. L'Echo des mines et de la métallurgie (12 de septiembre de 1904, p. 1080); Pérez (2011), pp. 341-347.

46. Bernal, Martínez y Florencio (2010), p. 218.

47. Los registros de minas de manganeso y cobre en los años cincuenta y sesenta en AHPH. JPF (búsqueda: Mora); Archivo Histórico Nacional. FC-M ${ }^{\circ}$ Hacienda, 3254, Exp. 966 (hoja de servicios de Joaquín); los préstamos hipotecarios en AHPH PN (4864, doc. 200; 4866, doc. $147 ; 4873$, doc. 147), etc.

48. En 1870 es consejero de la Compañía de ferrocarriles Sevilla-Huelva-Minas de Riotinto, promovida por C. Lamiable (Gómez, 1873, p. 371).

49. La Provincia (8 de marzo de 1885, p. 1; 4 de abril de 1890, p. 1); AHPH. PN (4892, doc. 268). 
verso, desde las finanzas (corresponsal del Credit Lyonnaise) a la construcción, pasando por la representación de empresas mineras (como Mines de Cuivre d'Aguas Teñidas), su especialidad es la viticultura: como cosechero, el estudio in situ del método de fabricación de La Charente le permite producir un cognac de Moguer que se exporta a ultramar y Europa, especialmente a la propia Francia, en cuya capital abre establecimiento en $1891 .{ }^{50}$

\section{La consolidación de la empresa familiar}

\section{La sucesión en un entorno económico complejo}

La mayor parte de los empresarios (con tres excepciones) de la primera generación va a morir entre 1898 y 1904, lo que permite establecer una relación entre el ciclo biológico de los empresarios y el ciclo de negocios en la provincia. Estos emprendedores fueron capaces de romper con las inercias del pasado y abrir un ciclo largo positivo que, para los contemporáneos, sentaba las bases de la modernización económica de la provincia. Sin embargo, sus sucesores se van a ver condicionados por un contexto adverso. En efecto, el relevo generacional llega en un entorno económico cada vez más complejo marcado por los cambios en el mercado internacional de metales que conducirán al fin de la época dorada de la gran minería durante la Primera Guerra Mundial (gráfico 1).$^{51}$ Ese difícil proceso de transición es definido por R. Terrades, presidente de la Sociedad Económica de Amigos del País, como «una época crítica en la que la ciudad tiene que sufrir grandes transformaciones para acomodarse a su nueva vida». ${ }^{52}$

Aunque la influencia de la primera generación de emprendedores es determinante en la conformación del entramado económico de la provincia, su principal legado serán sus sucesores. La fuerte personalidad de los fundadores se aprecia en la denominación de varias de las sociedades creadas por ellos o sus sucesores, de manera que es frecuente la denominación «Hijos de», o en el mantenimiento de la marca familiar, como sucede con «Matías López, Fundición», que todavía aparece en la publicidad en los años sesenta del siglo XX. Esta cuestión presta cohesión a estas empresas. ${ }^{53}$ Además, una sucesión ordenada es una de las claves del éxito de la longevidad de las empresas familiares. ${ }^{54}$ Ese es el caso de la más longeva de todas ellas, Hijos de Vázquez López,

50. Revista de Navegación y Comercio (10 de abril de 1892, p. 142); Le Panthéon de l'Industrie (1891, noviembre, n. ${ }^{\circ} 860$, pp. 281-82); Pérez (2011), pp. 319-324.

51. Ferrero (2000), pp. 122-140; Sánchez (2011), pp. 44-49.

52. La Defensa (6 de julio de 1907, p. 1).

53. Fernández, López y Gutiérrez (2014).

54. Díaz (2013); Gallo (1998). 
GRÁFICO 1 - Sector minero. Producción (Tm) / exportación (Tm) / Precios de piritas (ptas/Tm)

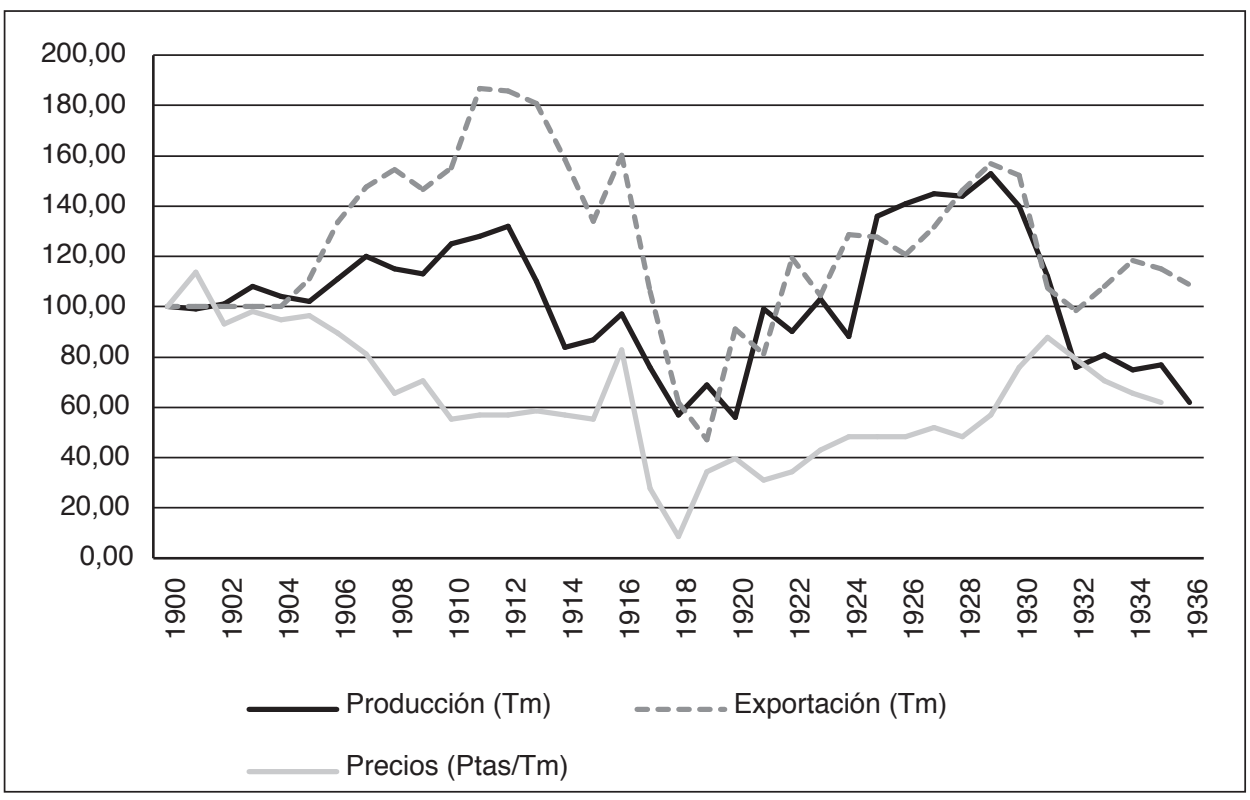

Fuente: Elaboración propia con datos de Carreras (2005, p. 437) y APH.

una sociedad cuidadosamente preparada por el fundador. En su testamento animaba a sus seis hijos a mantener los negocios emprendidos, a laborar por la prosperidad de Huelva y a «trabajar cada uno en su clase y circunstancias». ${ }^{55}$ Una de las claves del éxito de esta sociedad sería, precisamente, una adecuada división de responsabilidades en la gestión de la empresa entre sus hijos. ${ }^{56}$ Más allá de negocios secundarios tradicionales (como el mercado inmobiliario o el abastecimiento de aguas a la ciudad), la empresa se va a especializar en las actividades mineras y bancarias. En el primer caso, la explotación directa de las piritas de hierro de la Joya desde 1908 va a ser muy remuneradora. En 1924, además, la sociedad cierra un ventajoso acuerdo con la Pyrites Producers Association, la organización que controla el mercado europeo de esta sustancia, que le garantiza una indemnización de 4.000 libras (3.200 desde 1929), a cambio de cerrar estas instalaciones durante diez años. ${ }^{57}$ Las cifras de los inventarios de bienes de la empresa también muestran los buenos resultados de las minas de manganeso, utilizado como fundente, ${ }^{58}$ en los años

55. Archivo Municipal de Huelva (AMH). Fondo Díaz Herrero (FDH) (Carp. 213).

56. Miró (1994), p. 129.

57. AHPH. PN (36396, doc. 46); Pinedo (pp. 261-265 y 941-943).

58. Ferrero (2000), p. 188. 
de la posguerra europea, que en 1918 aportan casi 1.000.000 de pesetas de beneficio, que supone un $94 \%$ del total de este apartado contable en ese año. Sin la estabilidad financiera que aporta el negocio minero no se entiende el gran desarrollo de los servicios bancarios que ofrece la casa. De hecho, Hijos de Vázquez López se convierte en el gran banco provincial compitiendo con las sucursales de los bancos nacionales. Esa actividad se apoya en los tradicionales préstamos hipotecarios, pero sobre todo en una densa malla de relaciones de crédito con casas de comercio y entidades bancarias nacionales e internacionales. $^{59}$

Un caso muy distinto lo representa la sociedad Thomas Morrison y Cía. Los problemas de salud habían impulsado al fundador de la firma a preparar una planificada sucesión y, de hecho, para reforzar los lazos familiares convierte esa sociedad en limitada, con sede en Londres y con 1.000.000 de capital en 1898, que más adelante se registra también en Huelva, y cede su dirección a su sobrino Thomas, que «se ha identificado de tal forma con la índole de la casa, que al faltar yo continuará aquella con mi mismo nombre». ${ }^{60}$ Sin embargo, muerto el fundador (en 1901) no va a ser Thomas, que va a ser contratado como director del departamento comercial de RTCL, sino su hermano, John Morrison, quien se va a hacer cargo de la compañía.$^{61}$ Aunque inicialmente otro hermano, William, asume la dirección de la compañía en España, nuevos proyectos, como la participación en la construcción de un alto horno que RTCL pretendía levantar en Huelva, obligaron al presidente a fijar allí su residencia en 1908. El fracaso de esa iniciativa, en 1913, y los graves problemas de liquidez que arrastra la fundición tratan de ser enjugados, sin éxito, con la venta del patrimonio inmobiliario de la casa. Finalmente, la fundición fue adquirida por un grupo de trabajadores en 1914, significativamente el año en el que la sociedad fue liquidada. Después de varias sociedades fallidas, ${ }^{62}$ John Morrison se va a asociar con Francis K. Haselden en 1919, que trabajaba en RTCL y que era nieto del empresario que colaborara con Deligny, H. F. C. Hasselden. La sociedad Morrison-Haselden va a desarrollar sus actividades durante los años de entreguerras, aunque con un horizonte de negocios ya muy limitado: la empresa fundidora que sirvió de sostén al gran negocio de distribución a escala europea no va a llegar al último período alcista del sector en los últimos años veinte (gráfico 2); para entonces se había convertido en un provinciano almacén de metales. ${ }^{63}$

59. Archivo del Senado. Mariano Vázquez de Zafra, Legislaturas 1918-1919, 1919-1920, Rentas.

60. La Provincia (8-5-1901, s.p.).

61. Thomas también va a formar parte, con J. Browning, director de RTCL, del Consejo de Dirección de la Sociedad Productos Químicos de Huelva. AHPH. PN (36398, doc. 421).

62. AHPH. PN (1952, docs. 194 y 198; 14406, docs, 680, 691, 692, 709; 14403, doc. 158; 14404, doc. 185).

63. La Provincia (1 de enero de 1918, s.p.); Madrid científico (1925, n. ${ }^{\circ} 1.139$, p. 176). 
GRÁFICO 2 - Sector metalúrgico. Producción (Tm) / Exportación de hierro (Tm) / $1905=100$

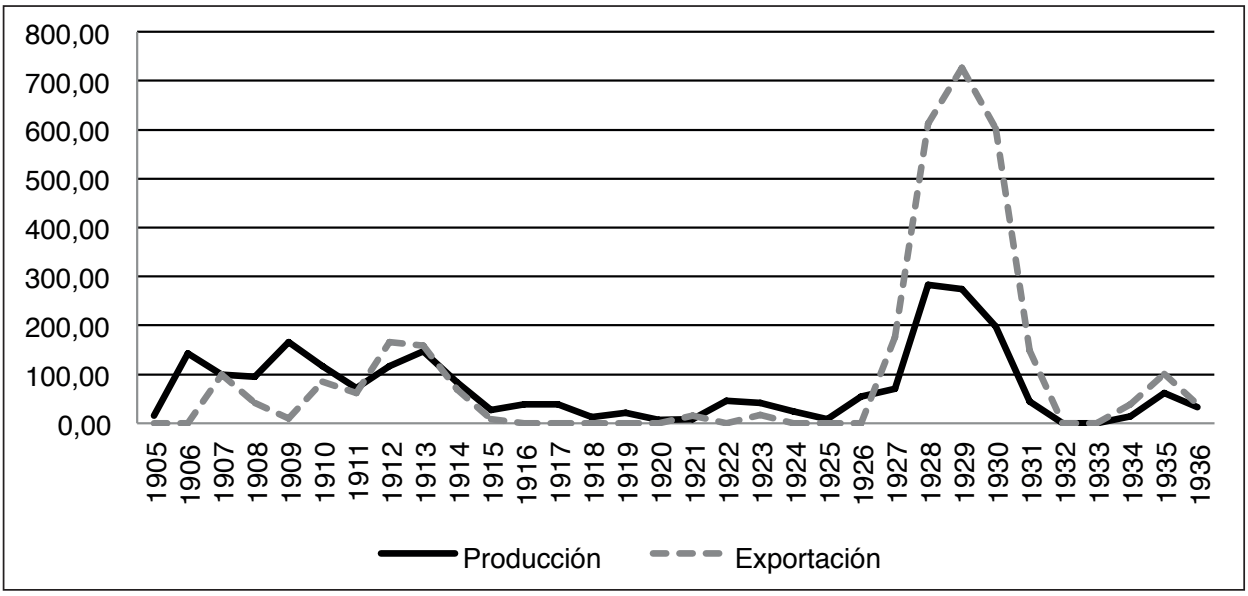

Fuente: Elaboración propia con datos de Parejo (2005, p. 172) y APH.

\section{El declive del negocio minero}

La segunda generación se enfrenta al desafío de adaptar la red empresarial construida por sus ascendientes a los nuevos tiempos. La primera respuesta es un progresivo alejamiento del sector minero. Es sintomático en este sentido que la nueva oleada inversora en el sector en la primera década del siglo $\mathrm{XX}^{64}$ no genere, como la primera, una nueva clase de empresarios. De hecho, la participación accionarial en estas nuevas compañías por parte de empresarios onubenses (y españoles) es testimonial y, más importante, su presencia en los consejos de dirección es excepcional: a esta tendencia solo escapan el empresario Antonio Guijarro (Mines de Cuivre de Campanario) y Carlos Sundheim (Compagnie des Mines de S. Platón), hijo de Guillermo Sundheim. ${ }^{65}$

Es verdad que el vínculo minero se va a mantener, a través de pequeñas participaciones, normalmente heredadas, en el accionariado de algunas empresas (de los Sánchez Dalp o de José Tejero González Vizcaíno en Sotiel Co-

64. Vinculada al alza del precio del cobre (Broder, 2015), pp. 108-109 y, especialmente, al nuevo ciclo del azufre (Ferrero, 2000, pp. 171-174).

65. Se han analizado ambas cuestiones en veinte compañías de capital alemán, francés y, sobre todo, inglés registradas entre 1899 y 1911, cuya documentación obra en el Centre des Archives du Monde du Travail (Roubaix, Francia) y en el National Archive (Londres). Véase también Ferrero (2000), pp. 415-425. 
ronada, por ejemplo $)^{66} \mathrm{y}$, sobre todo, gracias a las labores de representación, que requieren formación jurídica e influencia política, en las que se especializa, entre otros muchos (Gómez Jaldón, los Duclós, J. Sánchez Mora, etc.), el mismo José Tejero González Vizcaíno, siguiendo la tradición familiar. Así, trabaja para compañías como The United Alkali Company, Huelva Copper and Sulphur Mines Company o Minas Tinto y Sta. Rosa. ${ }^{67}$

Como muestra precisamente el caso de los sucesores de G. Sundheim, sobre todo después de la «crisis suprema del manganeso», la explotación directa va dejando paso a la cesión en arriendo a esas grandes empresas extranjeras. Carlos y Justa Sundheim, ${ }^{68}$ casada con el geólogo Carlos Doetsch — sobrino de E. Doetsch-, habían recibido en herencia de su tío Jorge Rieken dos importantes minas, Cabezas de Pasto y Herrerías. Como en la mina La Joya, el cobre de sus piritas va a ser extraído por The Bede Metal hasta 1911, año en el que van a ser arrendadas al gigante químico francés Saint Gobain. ${ }^{69}$

\section{Especialización, mercado interior e inversiones refugio}

Las dificultades de sectores tradicionales tales como el pesquero o el vitivinícola, muy vinculados a los mercados internacionales, afectan directamente a los negocios de las familias Jiménez y Tejero. La quiebra de la sociedad Francisco Jiménez y Compañía en 1903, relacionada probablemente con la plaga filoxérica, ${ }^{70}$ tiene como principal consecuencia la fragmentación del negocio familiar. Por una parte, Francisco y sus hijos Manuel e Ignacio Jiménez Jerez, que forman sociedad en 1907 y 1917, van a gestionar una fábrica de ladrillos. El negocio vinatero, con la prestigiosa marca Cognac Fino de Moguer, va a ser regentado por su sobrino Eustaquio Jiménez, alcalde de Moguer, aunque con poco éxito: su hermano, el nobel Juan Ramón Jiménez, opinaba que era «el tipo más completo de la ilusión fracasada» como mostraban sus proyectos vitales, entre otros el industrial. ${ }^{71}$ En realidad, Moguer no participó de la reactivación del sector vitivinícola del condado en los años veinte, apoyada en un incremento de la demanda, en la expansión de la superficie de cultivo y en el «ferrocarril del vino» (1921) (gráfico 3). ${ }^{72}$

66. AHPH. PN (1941, doc. 597).

67. Mojarro (2007), p. 76; Madrid científico (1906, n..$^{\circ}$ 537, p. 18).

68. El hermano mayor, Guillermo, crea en 1890 una sociedad con su tío Manuel de la Cueva dedicada a la comercialización de productos agrarios procedentes de la gran finca familiar de Peguerillas, que su padre le había arrendado (AHPH. PN, 4938, doc. 636; 4944, doc. 636). Sin embargo, muy pronto se traslada a Bélgica, en donde había contraído matrimonio (La Provincia, 26-11-1890, s.p.), abandonando los negocios en Huelva.

69. Pinedo (1963), pp. 234-237 y 365; Chastagnaret (2000), p. 577.

70. Pérez (2011), pp. 319-324.

71. Miró (1994), pp. 400 y 402; Fernández (2006), p. 21.

72. Peña (1995), pp. 136-137; Ramírez (2002). 
GRÁFICO 3 - Sector vitivinícola. Producción de mosto (HI) / Exportación (Tm) / $1905=100$

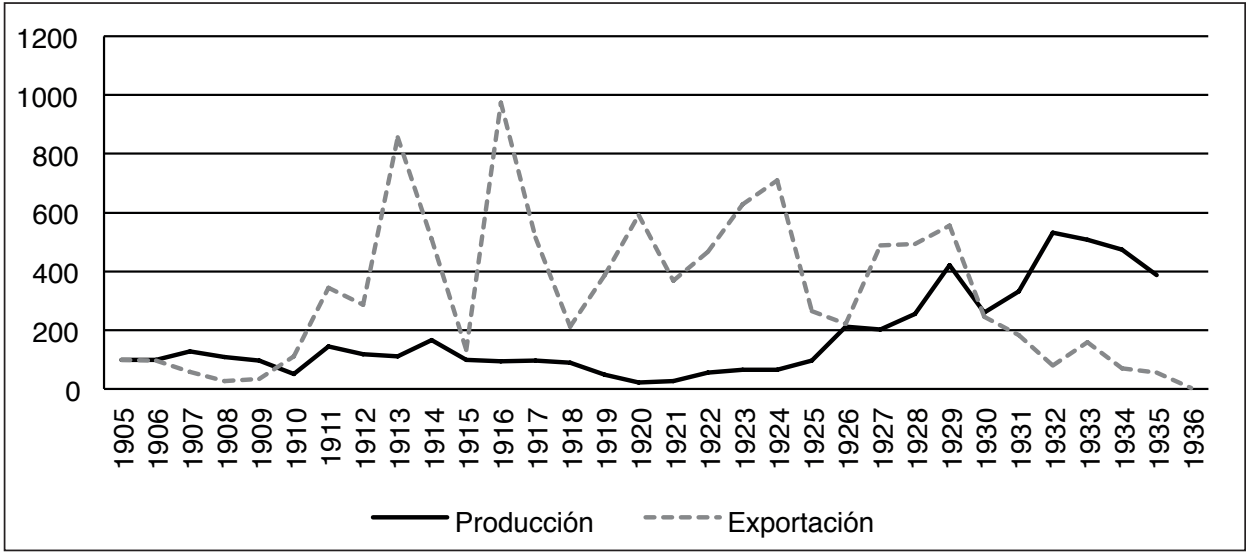

Fuente: Elaboración propia con datos de Parejo (2005, p. 204) y APH.

Los negocios mineros son solo la primera actividad de un empresario, Antonio Tejero González Vizcaíno, que desde la segunda década del siglo XX se dedica al sector pesquero, con la gestión desde 1916 de una fábrica de conservas y una traíña que emplea en 1920 a 125 obreros. Sin embargo, va a ser sobre todo conocido como el más conspicuo representante del sector pesquero provincial, sobre todo durante la Dictadura de Primo de Rivera. Tejero llegará a ostentar la presidencia de la Federación Española de Armadores y será miembro de la Asamblea Nacional en un complejo período, especialmente después de 1925, para la pesca provincial (gráfico 4). ${ }^{73}$

Por otro lado, la estrategia de diversificación puesta en marcha desde los años noventa por Matías López, en la que va a involucrar a sus hijos, y que implicaba la introducción en el sector vitivinícola (Bodega Los Santos Lugares) o naviero (barco de vapor Isla Saltés) y la expansión del negocio de metales, en sociedad con el empresario local Miguel Martín Cordero, a Ayamonte y el Algarve, se ve frenada después de su muerte acaecida en 1911. En realidad, como ocurrió con la familia Jiménez, el negocio se divide: mientras Antonio López Gómez va a heredar las bodegas, su hermano Joaquín, ingeniero e influyente hombre de empresa (fue presidente de la Cámara de Comercio $\mathrm{y}$ vicepresidente del puerto), va a gestionar la fundición, que, en su doble función como almacén de metales y taller, se va a mantener activa hasta la segunda mitad del siglo XX. ${ }^{74}$

73. Pérez (2011), p. 508; Ríos (2002), pp. 64-65. s.p.).

74. Pérez (2011), p. 328-329; AHPH. PN (36399, doc. 606); La Rábida (1931), p. 205, 
GRÁFICO 4 - Pesca capturada (kg) / Exportación conservas ( $k g$ ) / $1919=100$

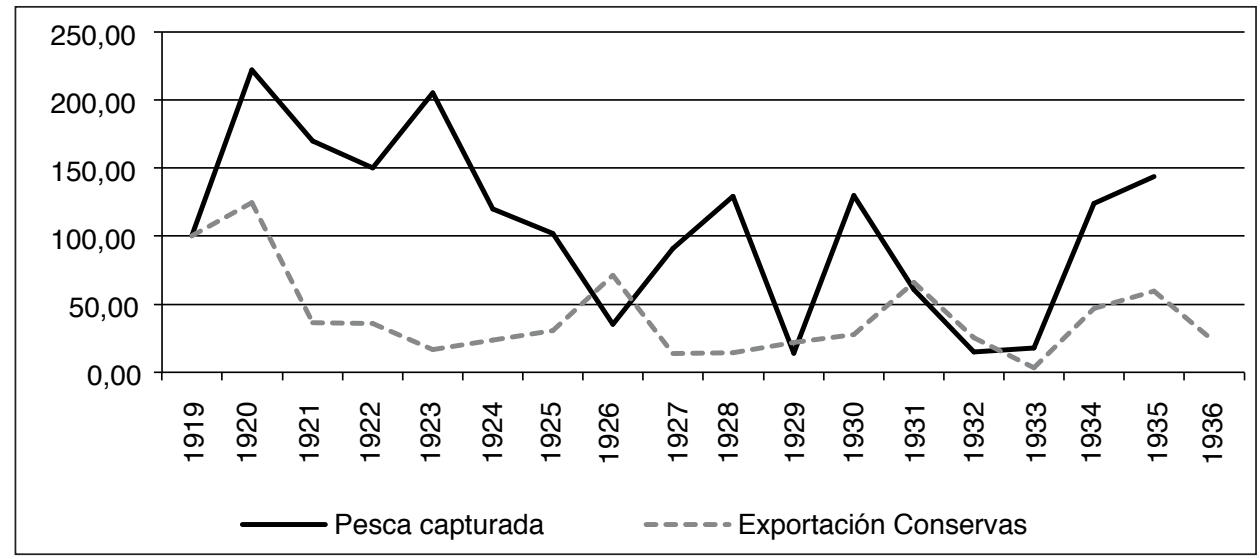

Fuente: Elaboración propia con datos de Ríos (2002, pp. 61 y 65) y APH.

Facilitadas por las actividades consulares de sus tres miembros, la sociedad Hijos de Eduardo Díaz (fundada en 1900 y modificada en 1907) va a dirigir, después de la muerte de su padre en 1899, una importante empresa de importación-exportación de maderas, especializada en vigas de coníferas escandinavas, austriacas y estadounidenses. El producto acabado se vendía en el mercado nacional, pero también se exportaba al norte de África. ${ }^{75}$ En los años veinte y treinta, abandonado ese negocio, hay una evidente inclinación en esa familia por acaparar bienes inmobiliarios en el inmediato extrarradio de la ciudad (avenida Sundheim, carretera Huelva-Sevilla, Tres Ventanas), pero también en el campo siguiendo la tendencia provincial (gráfico 5). De hecho, Enrique Díaz Franco de Llanos es el octavo contribuyente provincial por riqueza rústica en $1925 .^{76}$

Continuando la estela del padre, la segunda generación de los Sánchez Dalp (Miguel, Francisco Javier y Bernabé) van a combinar el negocio minero (reducido a la participación de Sotiel Coronada) con la gestación de un extenso patrimonio rústico, formado a partir de enlaces matrimoniales con la familia Marañón, pertenecientes a la burguesía agraria sevillana. Sin perder el contacto con Huelva, donde poseen propiedades y una enorme influencia

75. Nuevo Mundo (25 de septiembre de 1913, s.p.); AHPH. PN (1919, doc. 256; 11096, doc. $800 ; 14405$, doc. 417$)$.

76. AMH (Leg. 700/2, 921/15, 707 (A. 245), apellido D —Díaz Franco de Llanos-); Actas Capitulares (AC) (1921, pp. 253-254). Enrique llega a ser presidente de la Sociedad Cooperativa de Casas Baratas (AMH. AC, 1921, p. 251). AMH (Leg. 612). «Relaciones de contribuyentes rústica y pecuaria, 1925». Véase la huida de capitales de empresarios andaluces al sector inmobiliario en Arenas (2015, pp. 256-261). 
GRÁFICO 5 - Sector primario. Producción total agraria (ptas. corrientes) $/ 1900=100$

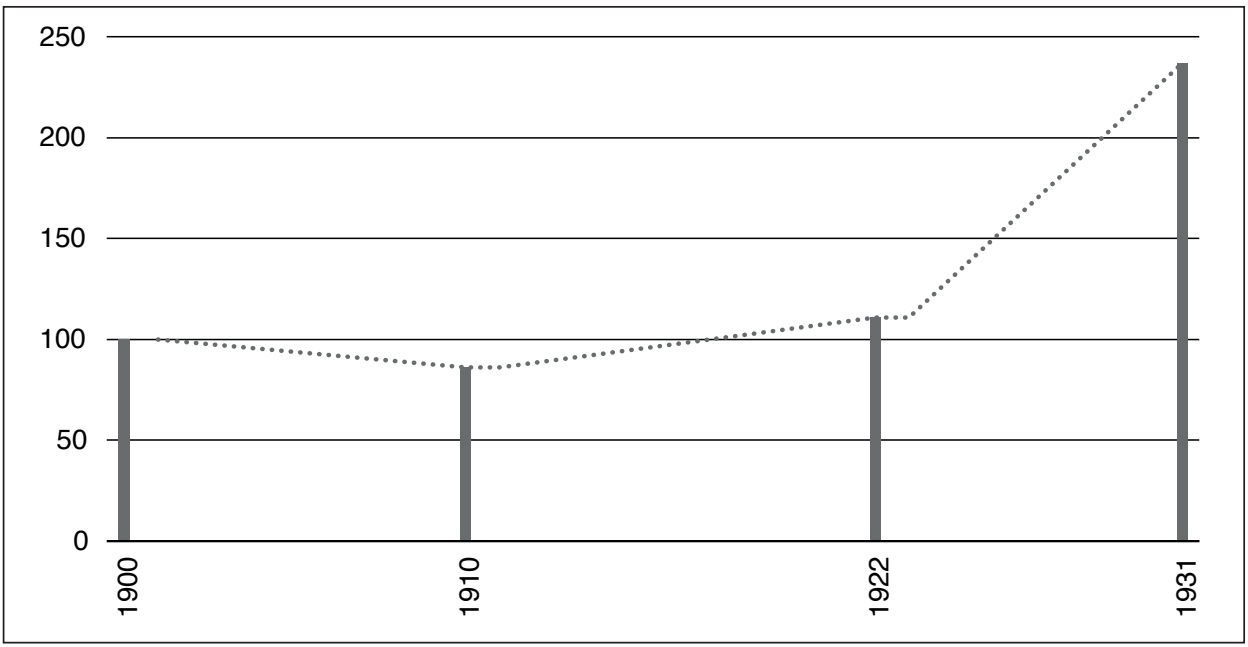

Fuente: Elaboración propia con datos de Parejo et al. (2002, pp. 456-459).

política desde el distrito de Aracena, ${ }^{77}$ se van a integrar en el mundo de los negocios sevillano de la época (especialmente Francisco Javier, vinculado al sector bancario, asegurador y editorial), y se van a ennoblecer a la vez que se especializan en la moderna gestión de la gran propiedad: Miguel Sánchez Dalp pasa por ser el «apóstol de todo desarrollo agrario» en España y su cortijo La Rinconada, «una finca modelo». ${ }^{78}$

La fábrica de superfosfatos de la razón social Wetzig-Weickert (que desde 1923 se denomina Wetzig, Weicker y Cía) atraviesa dificultades desde los años veinte. Los costes de transportes, las dificultades para la importación o la fuerte competencia en el mercado nacional, junto a la atonía de la demanda y las restricciones legales establecidas por el Gobierno (5\% de porcentaje máximo de minerales en abonos compuestos) limitan la producción al entorno de unas modestas $2.000 \mathrm{Tm}$ anuales ${ }^{79}$ si se las compara con las cifras de principios de siglo. Un perfil similar, por otra parte, al que muestra la evolución de los datos provinciales, como se aprecia en el gráfico 6.

77. Francisco Javier fue un ejemplo de «cacique estable» en la sierra, pues consiguió ganar todas las elecciones para el partido conservador desde 1896 hasta 1923 (Díaz, 2010, p. 426).

78. La Esfera (11 de diciembre de 1920, s.p.); La Voz de Menorca (2 de marzo de 1907, p. 2); Bernal, Martínez y Florencio (2010, p. 198).

79. El Debate (14 de septiembre de 1919, p. 6); AHPH. Delegación Provincial de Hacienda (DPH) (2501, n. ${ }^{\circ} 12$. s. n.). 
GRÁFICO 6 - Sector químico. Producción de superfosfatos (Tm) / Exportación piritas de hierro $(\mathrm{Tm}) / 1906=100$

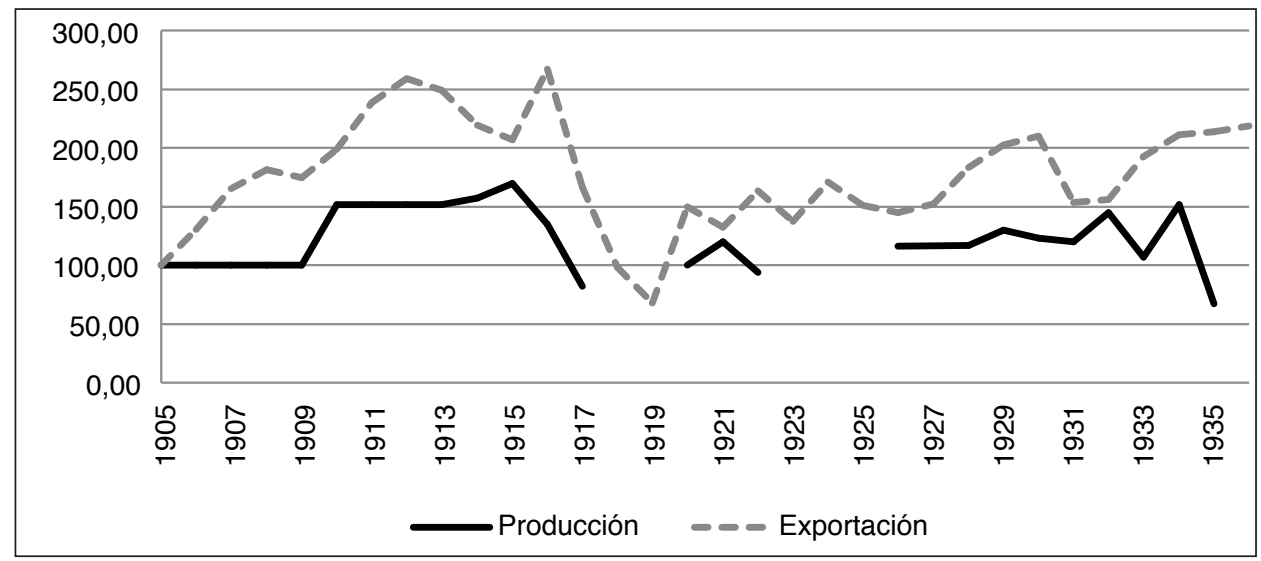

Fuente: Elaboración propia con datos de Parejo (2005, p. 208) y APH.

\section{Servicios urbanos e «industrialismo político»}

El desarrollo de las redes urbanas de servicios había dado lugar, desde finales del siglo XIX, a encendidos debates sobre la colusión de intereses políticos y empresariales ${ }^{80}$ que habían afectado a la familia Mora: a esas prácticas las denominan sus adversarios «industrialismo político». Después de la Gran Guerra, el debate va a alcanzar de lleno a Antonio de Mora y Claros, presidente de la Diputación, diputado y alcalde de la ciudad desde 1920. Por una parte, Hijos de Antonio Mora va a seguir siendo una de las dos compañías, junto a Hijos de Vázquez López, que abastecían de agua a la ciudad y cuya gestión va a ser objeto de fuertes críticas que, de hecho, van a llevar al Ayuntamiento a ceder ese servicio a una tercera empresa, Aguas de Huelva, en $1925 .{ }^{81}$ Pero van a ser las maniobras para hacerse con el suministro de la electricidad, un sector que debió verse muy afectado por la guerra mundial a juzgar por el perfil de la curva de producción que refleja el gráfico 7, las que van a desatar una campaña contra el alcalde. Su repentina muerte en 1922 pone en evidencia la irregular situación de la empresa: Sevillana, la nueva empresa adjudicataria en 1924, comprueba con sorpresa que no había existido ningún contrato oficial entre Antonio Mora y el Ayuntamiento. ${ }^{82}$

80. Véase esta compleja relación en España (Cabrera y Rey, 1994); en Italia o Grecia (Tortella y Quiroga, 2013, p. 222).

81. Diario de Huelva (25 de enero de 1931, pp. 1-2).

82. Pérez (2011), pp. 489-493. 
GRÁFICO 7 - Sector eléctrico. Producción de energía eléctrica (Mwh) / $1914=100$

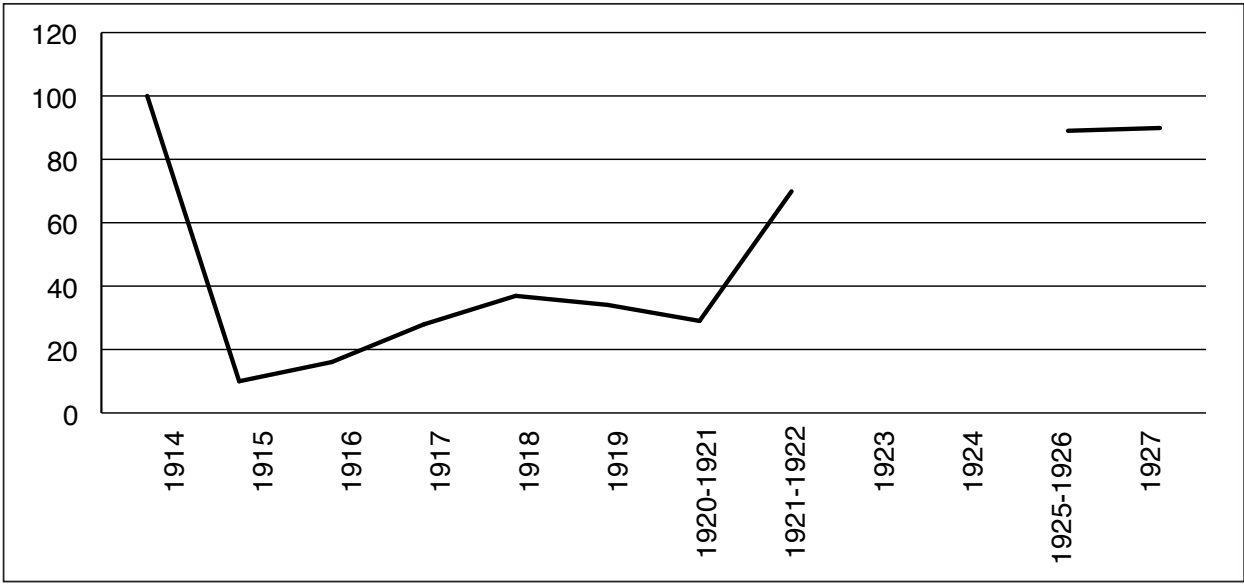

Fuente: Elaboración propia con datos de Parejo (2005, p. 189).

\section{La organización institucional}

Los empresarios compitieron en el mercado, pero también colaboraron abiertamente en la creación de una tupida e influyente malla institucional que va ser favorecida por un estado que adopta un estilo más regulador en materia económica y social y que, como consecuencia, impulsa el asociacionismo desde fines del siglo XIX. ${ }^{83} \mathrm{Si}$ bien se revitalizan organizaciones como la Sociedad Económica de Amigos del País (que nace en 1834) o el Círculo Mercantil y Agrícola (1863), la mayor parte surgen en los decenios interseculares: así, la Cámara Agrícola, la Cámara Oficial Minera, el Centro Comercial e Industrial o el Consejo de Agricultura, Industria y Comercio ${ }^{84}$ No obstante, los dos organismos de índole económica más importante, vinculados estrechamente al boom minero, serán la Junta de Obras del Puerto (JOP) y, sobre todo, la Cámara de Comercio, Industria y Navegación de Huelva (CCINH). La primera, nacida para impulsar una infraestructura que garantizara la conexión de la economía provincial con el exterior, fue fundada y dirigida por el grupo más dinámico de empresarios provinciales, entre los que destacan Vázquez López, Sundheim o la familia Jiménez, en 1874 y se va a convertir muy pronto en el pulmón económico de la ciudad. ${ }^{85}$ En realidad, la posición estratégica del

83. Cabrera y Rey (1994), p. 443.

84. Con un carácter socio-cultural se fundan en esos años también la Sociedad Colombina Onubense, el Club Onubense de Regatas, el Ateneo, el Casino, etc. (Odiel, 2 de mayo de 1963 , p. 11; 21 de diciembre de 1969, p. 8).

85. Su origen y evolución han sido analizados por A. M. Mojarro (2007). 
puerto (y la presencia de una aduana, tal y como se establece en la normativa) unida a las expectativas de negocio generadas por la llegada del capital internacional a la cuenca explican el temprano origen de la CCINH al amparo del Real Decreto de 9 de abril de 1886. Las cámaras nacían con un doble carácter público-privado, a imagen del modelo cameral francés, que va a marcar sus actuaciones, con funciones diversas que iban desde el asesoramiento a instituciones oficiales a la defensa de los intereses de los asociados. Esa doble faceta, que va a permanecer en el tiempo a pesar de los importantes cambios que trae la Ley de Bases de 29 de junio de $1911,{ }^{86}$ permite abordar el mundo empresarial onubense desde una perspectiva macroeconómica. En ese sentido es interesante señalar la posición de los empresarios que revelan las memorias anuales de la CCINH en dos aspectos esenciales interrelacionados: comercio exterior y transportes. El análisis del censo de asociados de esta institución y la evolución de las sociedades mercantiles, en tercer lugar, permitirán observar la actividad empresarial en el largo plazo.

La globalización impulsada por la gran minería hizo que una de las líneas prioritarias para los integrantes de la CCINH fueran las cuestiones relacionadas con los mercados exteriores, especialmente en los primeros decenios. Tan acreditada era a finales del siglo XIX su conocimiento del funcionamiento de las redes comerciales europeas que el Congreso de los Diputados le solicitó informes al respecto. ${ }^{87}$ En sentido inverso, en 1887 la CCINH presentaba un proyecto de creación de tribunales de comercio al Parlamento con el objetivo de reducir los problemas de los empresarios en sus transacciones internacionales, una propuesta derivada de la experiencia acumulada en Francia, pero también en Italia o Portugal, destino de la mayor parte de la producción vinícola y conservera de la provincia. ${ }^{88}$

En realidad, la dependencia de los mercados exteriores de la economía provincial convirtió a la CCINH en una abierta defensora del librecambismo. ${ }^{89}$ Una tendencia que se hace evidente con motivo de la implementación de políticas proteccionistas con inmediatos efectos en la economía local, como ocurrió desde tempranas fechas con las medidas de control de los vinos en aduanas de las autoridades galas ${ }^{90} \mathrm{y}$, muy especialmente, con el Arancel

86. Que refuerza su carácter público, mejora su financiación y establece la colegiación obligatoria (Saz, 1996, pp. 167-178; Bahamonde, Martínez y Rey, 1988; Suárez, 2003).

87. Archivo Cámara de Comercio, Industria y Navegación de Huelva (ACCINH), Memorias $(1888$, p. 5).

88. Ya en 1888 la CCINH envía un informe sobre los problemas arancelarios con Francia. Al año siguiente, Francisco Jiménez lidera una comisión de viticultores que se traslada a Madrid (ACCINH, Memorias, 1888, p. 9). Sobre el perfil exportador en el sector pesquero, véase Ríos (2002).

89. Como también ocurre con otras cámaras como la de Madrid (Bahamonde, Martínez y Rey, 1988) o la de Las Palmas (Suárez, 2003).

90. Véase nota 88 . 
Cambó en 1922 («el arancel de la muerte») ante el que la CCINH se opuso decididamente. ${ }^{91}$ Es muy significativo el rechazo a la Real Orden de 11 de diciembre de 1929, que regulaba las exportaciones de productos agrarios con vistas a mejorar su calidad, con el argumento de que «la libertad de comercio es casi siempre más conveniente para la circulación de la riqueza».$^{92}$ Ello no es óbice para que la Cámara se haga eco ocasionalmente de demandas de corte proteccionista de determinados grupos de empresarios, como los productores de ganado porcino de la sierra en 1908 o el Consorcio Nacional Almadrabero, la organización de los pescadores de la costa occidental, en $1928 .{ }^{93}$

Pero donde con más claridad se ponen de manifiesto las contradictorias relaciones entre la élite empresarial de la capital, apoyada en el sector minero del Andévalo, y los sistemas empresariales agroalimentarios de la costa occidental, el condado y la sierra, ${ }^{94}$ sea cuando las memorias de la CCINH se extienden en los graves problemas de la red viaria provincial. Los desequilibrios en este sentido son estructurales y tienen mucho que ver con la rígida dependencia de la red básica ferroviaria y portuaria, construida ya en los años ochenta, de los intereses mineros. A ello responde que los dos ferrocarriles largamente reclamados por los bodegueros del condado y por los conserveros de la costa occidental no se terminen hasta 1921 y 1939, respectivamente; ${ }^{95}$ o la cerrada oposición de la Cámara a cualquier línea, como Castillo de las Guardas-Sevilla, que evite el nodo logístico de Huelva. ${ }^{96}$ En lo que atañe al puerto, es significativo señalar que las importantes inversiones realizadas durante la dictadura primorriverista, que lo habían convertido en el segundo del país, llegan demasiado tarde: su especialización minera tras la crisis de 1929, una vez constatada la pérdida de parte del tráfico de las mercancías provinciales y la competencia que hace el puerto de Sevilla para atraerse a las extremeñas, lleva a afirmar a M. Pérez, un directivo de esas instalaciones, que «...este puerto es demasiado grande para Huelva». ${ }^{97}$

91. La Provincia (15 de febrero de 1922, s.p.).

92. ACCINH, Memoria (1930), p. 39.

93. La Justicia (4 de septiembre de 1908, s.p.); Ríos (2002), p. 64.

94. Rubio (2014), pp. 196 y 210.

95. La línea ferroviaria Huelva-Ayamonte, así como la mejora de la carretera entre ambas localidades, fue una reclamación constante tanto de la CCINH (ACCINH, Memorias, 1910, pp. 37-39; 1912, p. 17; 1928, p. 37) y, sobre todo, de la CCIN de Ayamonte (Delgado, 2014, pp. 23-24). Las instalaciones portuarias son también pésimas en la provincia y en la capital «el puerto está dedicado exclusivamente a la navegación; la pesca no encuentra refugio» (De Buen, 1922, p. 407, citado en Ríos, 2002, p. 62). Sobre el «ferrocarril del vino», véase Ramírez (2002).

96. ACCINH, Memoria (1910), p. 15.

97. Pérez (1932), p. 81. 
En todo caso, como ponen reiteradamente de manifiesto las memorias, ${ }^{98}$ el tráfico de minerales hace del puerto el centro neurálgico de la vida económica de la provincia. Por esa razón, y para terminar este epígrafe, se va a abordar una aproximación en el largo plazo a la evolución del tejido productivo a partir de dos índices de intensidad empresarial. El primero de ellos (gráfico 8) combina precisamente los censos de asociados que la CCINH publica desde 1912 con el registro de exportaciones del puerto. ${ }^{99}$ Tal como puede apreciarse en ese gráfico, la relación entre las dos curvas es indicativa de la estrecha vinculación entre la actividad empresarial y las oscilaciones del mercado exterior y, particularmente, del ritmo que marca el tráfico de sustancias mineras: hay que tener en consideración en este sentido que, en términos de tonelaje, el

GRÁFICO 8 - Intensidad empresarial (I): Huelva. Socios CCINH-Tráfico portuario / $1912=100$

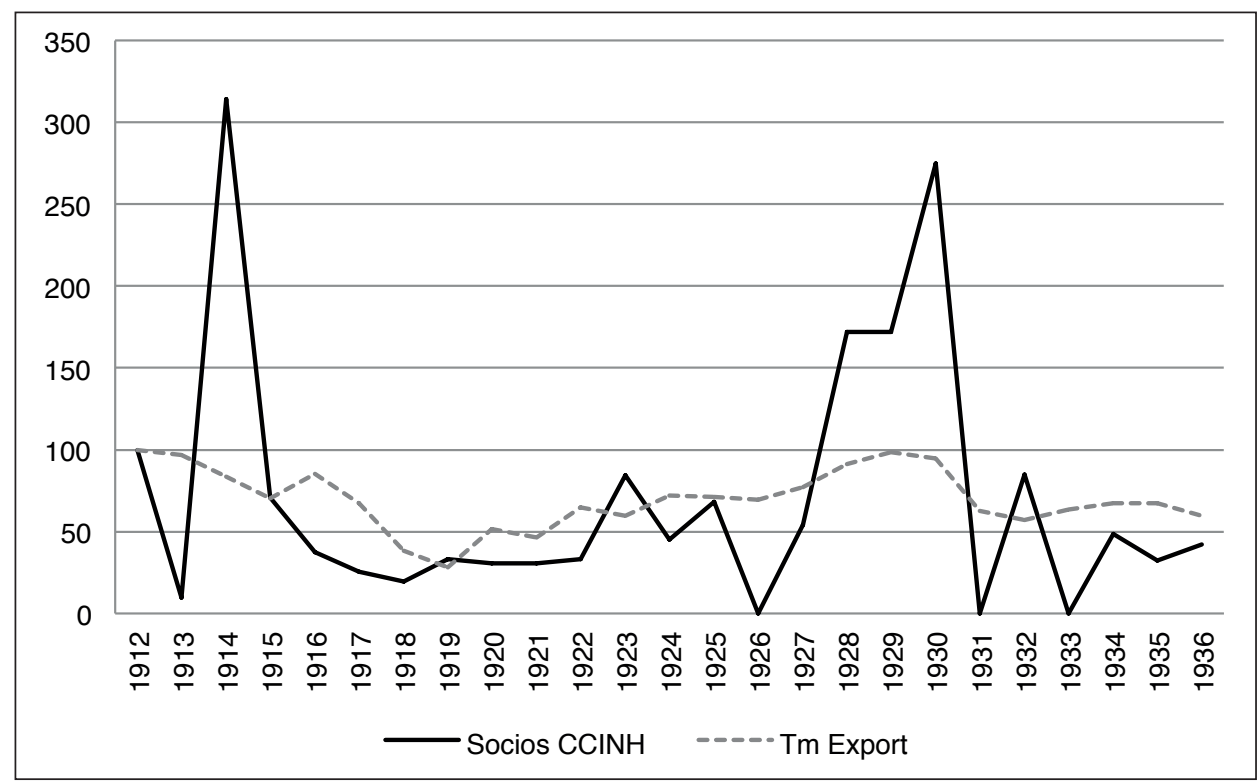

Fuente: Elaboración propia con datos de ACCINH —censos-y APH.

98. Por ejemplo, en la Memoria de 1912 (p. 49) se dice: «Una capital de 35.000 almas que desarrolla un comercio activo, a cuyo puerto afluyen cinco líneas férreas, formando estos elementos un centro de exportación de minerales superior al de toda otra capital de la $\mathrm{Na}$ ción...».

99. Los censos se elaboran a partir de la Contribución Industrial y Comercial, pues la Ley de Bases de 1911 fijaba la financiación de las cámaras a partir del pago obligatorio del 2\% de ese impuesto (Saz, 1996), p. 173. A pesar de los problemas de esta fuente fiscal que destacan los especialistas (Parejo, 1995, pp. 12-13), su adaptación para fines censales lo convierte en un interesante documento estadístico para medir la actividad empresarial en el tiempo. La información sobre movimiento de mercancías está extraída del APH. 
$91,8 \%$ de los productos que salen del puerto proceden del sector minero y una cifra similar, el 92,9\%, son exportaciones. La Primera Guerra Mundial aparece como un hito decisivo en esa evolución: la brusca caída de las exportaciones mineras debió tener un efecto inmediato en el entramado empresarial, especialmente en las pymes, tal como también señala la prensa del momento: «... las industrias pequeñas y el pequeño comercio...han visto disminuidos sus ingresos en más de un cincuenta por ciento [desde el estallido del conflicto]». ${ }^{100}$ El desglose de las cifras del subsector conservero y, en menor medida, del vinícola muestra una momentánea mejoría del sector agroalimentario en la etapa final de la guerra y, sobre todo, en la inmediata posguerra, que se traduce en un incremento temporal de las iniciativas empresariales. ${ }^{101}$ Sin embargo, no hubo efecto sustitución: las restrictivas políticas arancelarias debieron ejercer muy negativos efectos a medio plazo sobre el emprendimiento, que solo se recupera a finales de los años veinte, otra vez en relación con un postrero ciclo de alza minero que, sin embargo, acaba estrepitosamente con la crisis de 1929 y arrastra tras de sí a las empresas locales en los años treinta.

Si este índice es de carácter provincial, el segundo Índice de Intensidad Empresarial (gráfico 9) permite una comparación de carácter regional gracias a la utilización de los registros de sociedades mercantiles. ${ }^{102}$ Este gráfico confirma la cesura que significa la Primera Guerra Mundial, o más concretamente el final de la conflagración y la inmediata posguerra, en la evolución de la empresarialidad tanto en Huelva como en la propia Andalucia, una cuestión sobre la que han incidido otros investigadores. ${ }^{103}$ Pero también refleja el ritmo oscilante de las dos series provinciales y una menor correlación entre ambas, muy distintas del perfil más regular y menos fluctuante de las curvas correspondientes a las sociedades mercantiles andaluzas. Un perfil diferencial que se extrema en coyunturas críticas, como la propia Gran Guerra, y que pa-

100. El Reformista (12 de septiembre de 1914, p. 1).

101. Se aprecia esta tendencia también desde el punto de vista de las sociedades mercantiles, que experimentan un fuerte aumento en 1919 y 1920 (véase gráfico 9; Miró, 1994, p. 35).

102. La validez de esta fuente en el análisis de las redes y de la empresarialidad está sobradamente demostrada y presta una inestimable ayuda en la elaboración de estudios comparativos en el tiempo y en el espacio. Sin embargo, los propios especialistas reconocen que se trata de un acto jurídico que implica la «creación de la red», pero no su proceso (Garrués y Rubio, 2013, p. 141). Más importante es, a nuestros efectos, que no contemple ni, obviamente, a los emprendedores individuales ni, sobre todo, a muchas de las sociedades (especialmente mineras) que tienen su sede fuera del ámbito provincial (Rubio y Garrués, 2017b, p. 84). Por eso se ha considerado más representativa para el primer Índice de Intensidad Empresarial el censo de socios de la CCINH, mientras que se ha utilizado el registro de sociedades en el segundo. La información procede de las cifras que da el propio registro onubense (Archivo del Registro Mercantil de Huelva, ARMH, Libros Registros, 1-16), una fuente también utilizada por Garrués, Hernández y Martín (2002), pp. 820-822 y Miró (1994). El Índice de Empresarialidad resulta de la ratio entre empresas constituidas por cada diez mil habitantes (Rubio, 2014, pp. 310-312).

103. Martín, Garrués y Hernández (1999); Rubio (2014), p. 50. 
GRÁFICO 9 - Intensidad empresarial (II): Huelva-Andalucía. Sociedades constituidas Índice de empresarialidad / $1900=100$

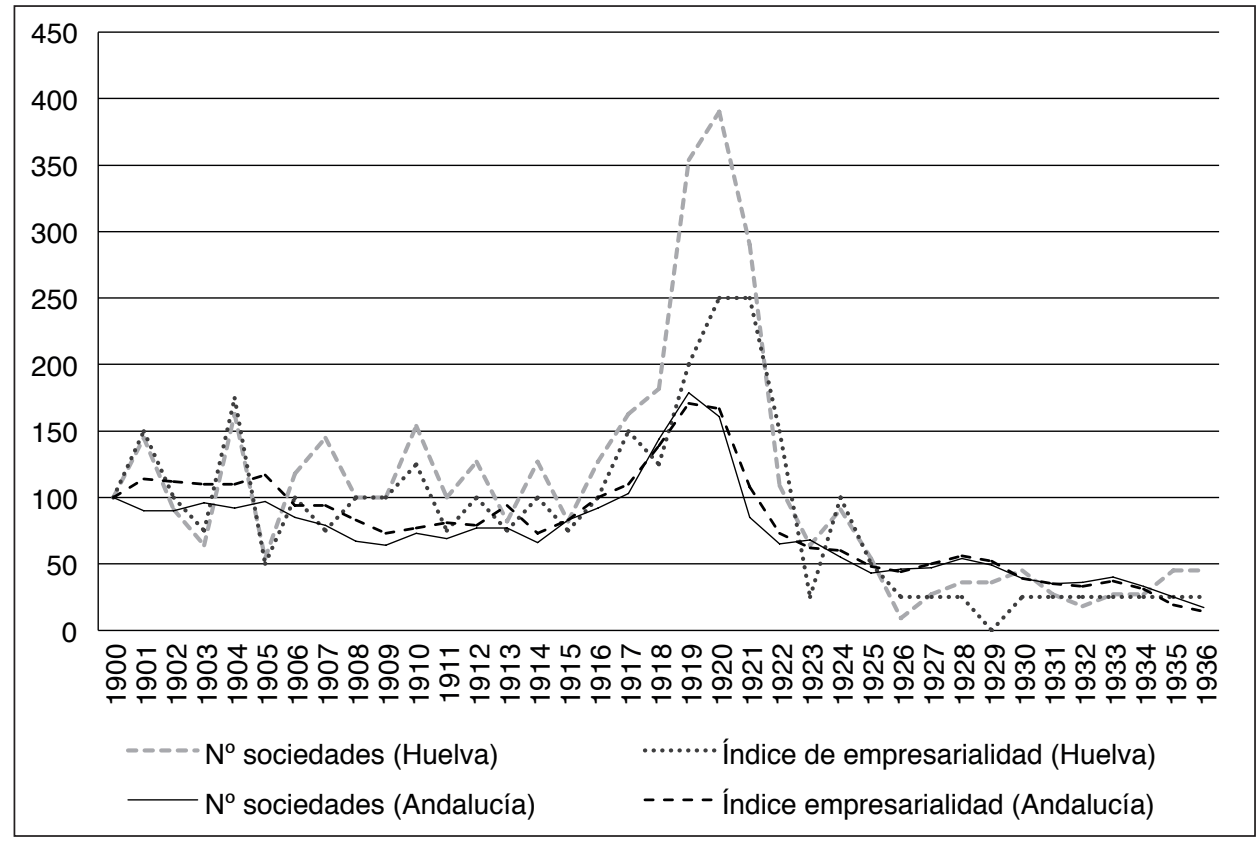

Fuente: Elaboración propia con datos de Garrués, Hernández y Martín (2002, pp. 821-823) y Rubio (2014, pp. 310312).

rece responder a la alta exposición a los mercados exteriores de las empresas onubenses. $^{104}$

\section{Disponibilidad de recursos, marco institucional y tejido empresarial: algunas consideraciones finales}

En los decenios centrales del siglo XIX un selecto grupo de empresarios nacionales y extranjeros acudieron a la faja pirítica onubense atraídos por el «Dorado minero». Cosmopolitas, bien relacionados con las redes internacionales de negocios y con una cuidada formación (universitaria en la mayor par-

104. De los inmediatos y negativos efectos de la guerra mundial son ilustrativas las opiniones de los medios y de los propios empresarios locales. Así, José Tejero afirmaba ya en agosto de 1914 que «... el funestísimo azote de la guerra internacional lo sufrirá la provincia de Huelva con mucha mayor intensidad que las demás provincias españolas» (La Provincia, 4 de agosto de 1914, s.p.). En el periódico El Reformista (14 de noviembre de 1914, p. 1) se señalaba la causa: «Huelva y su provincia, por la índole especial de sus principales industrias y su comercio, es la región de España que siente más las salpicaduras de la espantosa conflagración que el mundo padece». 
te de los casos) y una abierta inclinación a participar en el mundo cultural, parecían reunir dos factores de producción «inmateriales» claves relacionados con la innovación schumpeteriana: el capital social y el capital humano. ${ }^{105}$ A ese perfil schumpeteriano se aproximan una serie de iniciativas innovadoras, normalmente imitativas en el sentido que le daba Baumol, vinculadas a los mercados exteriores (creación de redes comerciales en Inglaterra o Portugal - Morrison, Sundheim, Matías López-, apertura de centros de distribución en Francia - Francisco Jiménez-, etc.) y al sector industrial, en forma de la más común de las innovaciones, la tecnología. ${ }^{106}$ La segunda condición, según Liebenstein, que abunda en ese perfil está relacionada con la minimización de la incertidumbre subjetiva de Knight: ${ }^{107}$ el mito de la California del cobre es muy útil en ese sentido, pues se trata de un análisis de futuro sobre las posibilidades económicas y empresariales de la provincia que ofrecía un muy optimista «horizonte de expectativas». En realidad, esa «mentalidad innovadora» ${ }^{108}$ se conjugó inicialmente con unas favorables condiciones del entorno, muy dependientes por otra parte del boom minero. Una relación que se entiende mejor si atendemos a que los tres mayores logros de estos emprendedores tienen un evidente componente social: la creación de dinastías empresariales que en algunos casos llegan a nuestros días, la organización de una red densa de instituciones formales e informales controladas con mano de hierro hasta el siglo $\mathrm{xx}^{109} \mathrm{y}$, como colofón, el primer impulso relevante en el camino a la industrialización, liderada por estos emprendedores.

Sin embargo, este ciclo empresarial comienza a mostrar los primeros signos de agotamiento en torno al cambio de siglo. Hasta entonces, los riesgos fueron en buena medida minimizados gracias a la diversificación, ${ }^{110}$ pero, sobre todo, a los canales de información y crédito y a las oportunidades de negocio que prestaba la proximidad a las redes internacionales y a las grandes

105. Tortella y Quiroga (2013), p. 2.

106. La escuela evolucionista, de inspiración schumpeteriana, considera la industrialización un proceso a largo plazo que consiste en una «acumulación de capacidades» y coloca la innovación como el elemento clave del cambio técnico y de la especialización productiva (Badía-Miró, Pinilla y Willefald, 2015, p. 9). A este efecto, y aunque se han señalado reiteradamente las limitaciones de esta fuente, las patentes permiten una primera aproximación a este indicador (Sáiz, 1999). La primera generación de emprendedores es responsable de diecinueve patentes (la segunda solo de tres), que suponen el 22\% (3\% en la segunda) de todos los registros en la provincia. Información disponible en: http://historico.oepm.es/buscador.php (término de búsqueda: Huelva).

107. Valdaliso y López (2007), p. 16.

108. Una expresión utilizada por Nadal (1984), p. 55, para referirse a los protagonistas de la primera industrialización andaluza.

109. La recuperación actual de la idea schumpeteriana sobre las recíprocas influencias de las empresas y las instituciones en Wadhwani y Lubisnsky (2017), p. 777.

110. Responden al tipo de «empresarios ubicuos» marshallianos característicos de las primeras fases de la industrialización (Mokyr, 2010, p. 192; Tortella y Quiroga, 2013, pp. 223224). 
firmas. Sin embargo, la creciente debilidad de las redes ${ }^{111} \mathrm{y}$, sobre todo, el alejamiento de las compañías líderes de los emprendedores locales pone a estos últimos en serios aprietos. Así, la desaparición de los anuncios sobre la evolución de los mercados de minerales de hierro de los Morrison en las revistas especializadas evidencia el descrédito de una gran marca basada en el intercambio de información de su red europea. Por otro lado, los problemas de liquidez del empresariado ${ }^{112}$ estallan en 1903 cuando dos de los más importantes banqueros provinciales, G. Sundheim y F. Jiménez, quiebran. Esa trampa de las expectativas fue, significativamente, inducida por las estrechas relaciones con las grandes empresas, ${ }^{113}$ pero también por el cambio en la gestión de RTLC en torno al cambio de siglo. En efecto, la «nueva cultura de empresa» impulsada con la llegada al accionariado de la compañía de los Rothschild y de nuevos directivos como J. J. Keswick y C. Fielding permitió abordar una profunda reorganización interna. En muchos casos esas iniciativas debilitaron las relaciones económicas de la compañía con los empresarios locales. Así, los canales de información de la empresa, en los que se habían especializado algunos empresarios, se centralizaron, estandarizaron y tendieron a despersonalizarse. A la vez, el tiempo de los poderosos agentes individuales llegó a su fin: el más caracterizado de ellos, E. Doetsch, fue destituido en $1894 .{ }^{114}$ Por otro lado, la tendencia a la verticalización de las actividades industriales de RTCL entró en colisión con los intereses de los emprendedores locales: el declive de los grandes proyectos en el sector minero-metalúrgico del propio Sundheim coincide con el alejamiento de su sociedad de esta firma desde 1894; del mismo modo, la negativa de RTCL a construir los altos hornos asestó un golpe definitivo al negocio de hierros de los Morrison. Ambas son manifestaciones de las insuperables barreras de entrada establecidas por las compañías mineras. ${ }^{115}$ En el fondo, la función básica que tan bien cumplieron estos empresarios pioneros y que hizo posible el aterrizaje de las grandes compañías, la minimización de costes de transacción e información, carecía a estas alturas de sentido y está detrás de un distanciamiento que fue clave en la estabilidad de sus negocios.

111. Cuando los entornos económicos evolucionan y se formalizan, las redes originales tienden a perder consistencia (Garrués, Rubio y Hernández, 2013, p. 112).

112. Como se sabe, además del papel de los empresarios pioneros y de las innovaciones, el tercer factor clave en la activación de los ciclos de negocios schumpeterianos y del propio desarrollo económico es el crédito (Hagemann, 2015, p. 125).

113. Aunque puede estar relacionada también con la sobreestimación de la capacidad de los empresarios (Mokyr, 2010, p. 194), lo que derivaría en una reacción muy negativa, de aversión a la pérdida, ante un entorno económico cada vez más complejo (Frydman y Phelps, 2013).

114. Harvey (1981), p. 14; Arenas (1999), p. 33.

115. Arenas (2015), p. 231. 
Además, y a pesar del legado patrimonial, de la buena formación recibida y de su carácter cosmopolita, la segunda generación de empresarios se enfrentó a un entorno económico marcado por los crecientes problemas para la gran minería onubense. ${ }^{116}$ Fue la Primera Guerra Mundial la que puso en evidencia las debilidades de un modelo económico con un grado de dependencia del mercado de minerales tan abrumador: la evolución del tejido empresarial, según el censo de asociados de la $\mathrm{CCINH}$, tuvo una trayectoria declinante similar a la de las exportaciones durante el período de entreguerras, que se agudiza después de la crisis del 29. La marea proteccionista en ese período hizo que el mercado exterior pasara de ser la solución a la economía onubense a ser el problema: de hecho, en un acta municipal se llegó a afirmar que los aranceles «darían lugar a la muerte de nuestra industria minera». ${ }^{117}$

En un clima de creciente incertidumbre, la mayoría de los empresarios trató de adaptarse a la nueva situación, alejándose del sector minero, replegándose sobre el mercado interior a la búsqueda de inversiones refugio o prevaliéndose de su posición política para progresar en los negocios, dando pie al fenómeno del «industrialismo político». Es en este contexto de declive minero cuando adquiere todo su sentido hablar de una oligarquía rentabilista, que se identifica con una "economía extractiva», tal como recientemente se ha calificado al modelo que representa RTCL. ${ }^{18}$ Una interpretación que se nutre de la discusión sobre el papel de la minería en la economía nacional y que es de talante marcadamente pesimista, ${ }^{119}$ pero que tiene también conexiones con diversas corrientes críticas como la teoría de la maldición de los recursos. ${ }^{120}$ Investigaciones recientes en este campo han hecho hincapié, sin embargo, en la complejidad de las relaciones entre abundancia de recursos y crecimiento económico insistiendo, entre otras cuestiones, en su carácter evolutivo, ${ }^{121} \mathrm{y}$ en la calidad de las instituciones como elemento clave. En este último sentido, aunque se considera tradicionalmente que la liberal Ley Minera de 1868 creó el marco institucional apropiado para la llegada del capital extranjero a la minería española, sin embargo, las legislaciones previas de 1849 y 1859 prepararon el camino a los emprendedores onubenses, que sirven de puente a las grandes empresas, que, a su vez, comienzan a llegar en los años sesenta por

116. Ferrero (2000), pp. 95-107; Sánchez (2011), pp. 44-49.

117. AMH. AC (26 de agosto de 1921, p. 223).

118. Arenas (2017).

119. Sánchez (2011), pp. 49-52; Escudero (1996).

120. Auty (1993).

121. Destacando ejemplos, como el de Huelva, de economías abiertas y especializadas en materias primas que después de alcanzar el éxito experimentan graves problemas estructurales en el medio y largo plazo. Un excelente resumen de esas nuevas líneas de investigación en Badía-Miró, Pinilla y Willefald (2015), pp. 1-25. 
cuestiones de demanda. ${ }^{122}$ En todo caso, el favorable clima institucional creado se va a ver seriamente perturbado por las tensiones derivadas de los problemas de contaminación (la denominada por la prensa de la época «cuestión de los humos») en la cuenca. Es significativo que la resolución en los años noventa de esta cuestión derivara en una redefinición de los derechos de propiedad $^{123}$ extraordinariamente ventajosa para RTCL que impulsó el desarrollo de toda una serie de mecanismos sociales y políticos que le van a dar un desmesurado poder, calificado por un contemporáneo como un «feudalismo industrial jamás visto». ${ }^{24}$

Volviendo al ámbito estrictamente empresarial, es a partir de entonces, como se adelantaba, cuando efectivamente se multiplican los comportamientos oportunistas y rentabilistas, al estilo del emprendedor kirzneriano, reproduciendo en su extremo unas actitudes que después de la Primera Guerra Mundial se extenderán por otras cuencas mineras andaluzas. ${ }^{125}$ Esa nueva actitud está también relacionada con una dolorosa constatación: la actividad extractiva, al contrario de lo que defendieron los ingenieros liberales desde mediados del siglo XIX, no fue el germen de un activo centro metalúrgico y químico con características de distrito. ${ }^{126}$ En cierto sentido, este tipo de aglomeración industrial respondía a los intereses comunes del sistema empresarial minero del Andévalo y del redistribuidor, ubicado en la ciudad, ${ }^{127}$ sobre todo desde los años noventa. Para un contemporáneo era el momento clave, una vez construidas las infraestructuras de transporte y garantizada la llegada de capitales extranjeros, en el que «la provincia debía entrar en su segundo período, o sea, el de la creación de muchas industrias». ${ }^{128}$ La localización de parte de esas industrias en el sureste de la capital ofrecía ventajas evidentes, pues era una zona de marismas bien conectada con las infraestructuras ferroviarias y portuarias y próxima a las instalaciones de RTCL: de hecho, esos terrenos fueron adquiridos en esos años por varios importantes empresarios, con una participación destacada de la colonia alemana, para, inicialmente, levantar fábricas (como la de guano) y almacenes. El Ayuntamiento también promueve, en sus Ordenanzas de 1893, el traslado de aquellas actividades económicas que pudieran resultar peligrosas para esa «zona industrial» alejada de la población. ${ }^{129}$ Con esas iniciativas se trataba de aprovechar

122. Broder (2015), p. 72.

123. Garrido y Pérez (2016).

124. Chastagnaret (2017), p. 251; Peña (1993).

125. Arenas (2015), p. 272.

126. Sobre las dificultades de la gran minería para generar esos distritos en España, véase Chastagnaret (2002).

127. Es útil a este respecto distinguir, como hacen Rubio y Garrués (2017b), p. 83, entre sistema empresarial y distrito.

128. La Provincia (30 de enero de 1890, s.p.).

129. Pérez (2015), p. 16. 
las sinergias derivadas de una eficiente relación entre pymes y grandes empresas, que podía ser especialmente beneficiosa, tal como Marshall defendía, para las primeras. ${ }^{130}$ Esa fue la intención del empresariado local, bien representada por los Morrison o por Sundheim y Doetsch, cuya participación en las grandes corporaciones mineras estuvo directamente relacionada con sus propios proyectos. El distrito ofrecía la posibilidad de retener población obrera (recuérdese el perfil inmobiliario de algunos de estos empresarios) y de promover la «atmósfera industrial» marshalliana que favoreciera la innovación, pero, sobre todo, era el medio para crear industrias auxiliares, el verdadero objetivo de estos emprendedores. ${ }^{131} \mathrm{Sin}$ embargo, los planes de RTCL no contemplaban esa opción. Como se ha visto más arriba, sus nuevas estrategias de diversificación productiva y de reorganización interna en torno al cambio de siglo eran incompatibles con esos objetivos. Un reciente análisis de los sistemas empresariales mineros a escala andaluza muestra que la capacidad de integración vertical de las grandes empresas mineras de la cuenca, y particularmente de RTLC, no hicieron posible la organización de un distrito, al contrario de lo que, por ejemplo, ocurrió en Linares-La Carolina, «dejando poco espacio para otras iniciativas y configurando economías de enclave». ${ }^{132} \mathrm{La}$ situación se agravó cuando el ciclo minero cambió después de la Primera Guerra Mundial: así, en los años treinta, el directivo del puerto M. Pérez considera que no hay ninguna industria que, en caso de un colapso del comercio de minerales, pueda sobrevivir. ${ }^{133}$

La dinámica de redes ofrece una explicación que abunda en esa pesimista visión. El nuevo clima económico tras la Primera Guerra Mundial puso en evidencia las profundas divisiones en la clase empresarial local, lo que va a contribuir al retraso en la conformación de un mercado interior cohesionado y,

130. Becattini (2002, p. 11).

131. Rubio y Garrués (2017b, p. 82).

132. Ibid. (p. 111). Al respecto es ilustrativa la contundente opinión de L. de Andrés (1910, p. 17), oficial de la aduana de Huelva: «... la industria en nuestra provincia, podemos decir que, en la verdadera acepción de la palabra y teniendo en cuenta su desenvolvimiento y desarrollo, es casi nula».

133. Pérez (1932, p. 91). Sus efectos sobre el tejido productivo, combinados con las consecuencias de la Guerra Civil y la posguerra, se dejarían notar a largo plazo: es significativo que en los informes previos a la creación del Polo de Promoción Industrial en los años sesenta, a partir del cual se pone en marcha definitivamente el proceso industrializador, se haga mención reiteradamente a la carencia de instalaciones de este tipo describiendo a la provincia como «un desierto agrario donde una chimenea industrial no puede ser más que un milagro» (Pérez, 2015, p. 16). Por otra parte, con la excepción de algunos casos aislados (como el de «Hijos de Matías López»), las sagas empresariales que lograron mantenerse activas no parece que tuvieran una participación activa en el Polo. En realidad, a pesar de que ese era uno de los objetivos de los planes de desarrollo, las pymes locales no fueron integradas en el Polo: solo un $16 \%$ de sus proyectos fueron inicialmente aceptados lo que implicó «una ausencia casi total de las pequeñas y medianas empresas dentro de los sectores derivados de las industrias pesadas... y en las industrias del sector servicios» (Fourneau, 1978, pp. 55 y 73). 
como es característico de las economías de enclave, ${ }^{134}$ al aislamiento de la economía provincial. La abierta inclinación por el librecambismo y, sobre todo, las carencias de la red de transporte, que responden a los intereses de las grandes compañías mineras y del nodo logístico de Huelva, llevan a diferencias irreconciliables entre los cinco sistemas empresariales provinciales. En realidad, la alianza entre la burguesía de negocios de la capital y las compañías mineras del Andévalo, responsables del impulso modernizador, nunca fue capaz de integrar a los otros tres sistemas empresariales agroalimentarios, los del condado (vinícola), la sierra (ganadero) y la costa occidental (pesquero). Por otro lado, la organización piramidal de muchas de las sociedades onubenses, caracterizadas por múltiples relaciones horizontales entre los emprendedores locales y sustentadas en muchos casos en una compañía internacional, explica en parte la escasa conectividad de las redes empresariales locales con las del resto de Andalucía. ${ }^{135}$ De forma excepcional, algunos de estos empresarios, como la familia Sundheim o los Sánchez Dalp, optaron por romper esa línea aislacionista al estrechar relaciones con la gran burguesía de la capital andaluza, siguiendo la tendencia a la «sevillanización» de la industria andaluza, ${ }^{136}$ aunque no sin pagar un alto precio: Francisco Javier Sánchez Dalp, el cacique estable de Aracena, fue objeto de una dura campaña por parte de La Provincia, portavoz oficioso de RTCL, en el que se le acusó de defender sus intereses económicos y los de sus «amigos sevillanos» (los Ibarra) por encima de los intereses de la provincia (y del puerto) en el asunto del ferrocarril de Castillo de las Guardas-Sevilla. ${ }^{137}$ Una cuestión económico-empresarial que termina por derivar en un conflicto político. En efecto, los argumentos tradicionales sobre la competencia «deshonesta» que el puerto sevillano hace al de Huelva sirvieron de punto de partida a una campaña con trasfondo político en la República: en ese contexto, distintas personalidades e instituciones provinciales (entre ellas la CCINH) van a plantear la conveniencia de aceptar por razones económicas una futura unión con Extremadura en detrimento de la adhesión a la Mancomunidad andaluza, promovida desde Sevilla. ${ }^{138}$

134. La relación entre economías de enclave, colonialismo y dependencia exterior es una de las líneas argumentales de la controversia sobre la minería española, especialmente si se trata de las compañías onubenses (Pérez y Sánchez, 2015, p. 51; Arenas, 2015, p. 231; Broder, (2015), p. 90. Desde un punto de vista empresarial, véase Rubio y Garrués (2017b), p. 109.

135. Rubio (2014), pp. 186-187. La falta de conexiones con la red andaluza es, por ejemplo, evidente en el gráfico 3 del trabajo de Garrués y Rubio (2013), p. 154.

136. Bernal, Martínez y Florencio (2010), p. 219.

137. La Provincia (18 de marzo de 1911, s.p.; 21 de marzo de 1911, s.p.).

138. Pérez (1932). 


\section{Bibliografía}

Amit, Raphael; Glosten, Lawrence y Muller, Eitan (1993), «Challenges to theory development in entrepreneurship research», Journal of Management Studies, 30: 815-834.

ANDrÉs, Luis B. de (1910), Provincia de Huelva. Memoria de valoraciones para el año 1905, Establecimiento tipográfico de Antonio Marzo, Madrid.

Arenas, Carlos (1999), Empresa, mercados, mina y mineros: Rio Tinto 1873-1936, Universidad de Huelva, Huelva.

- (2015), Poder, economía y sociedad en el sur. Historia e instituciones del capitalismo andaluz, Centro de Estudios Andaluces, Sevilla.

- (2017), «Riotinto, el declive de un mito minero (1954-2003)», Revista de Historia Industrial, 69: 109-142.

AuTY, Richard (1993), Sustaining development in mineral economies: the resource-curse thesis, Routledge, Londres.

Badia-Miró, Marc; Pinilla, Vicente y Willefald, Henry (eds.) (2015), Natural resources and economic growth: Learning from history, Routledge, Londres.

Bahamonde, Angel; Martínez, José A.; Rey, Fernando del (1988). La Cámara de Comercio, Industria y Navegación de Madrid, 1887-1987. Historia de una institución centenaria, Cámara de Comercio, Industria y Navegación, Madrid.

BecAttini, Giacomo (2002), «Del distrito industrial marshalliano a la "teoría del distrito" contemporánea. Una breve reconstrucción crítica», Investigaciones Regionales, 1: $9-32$.

Bernal, Antonio M.; Martínez, José I. y Florencio, Antonio (2010), El empresariado andaluz, en perspectiva histórica, Escuela Andaluza de Economía, Sevilla.

Broder, Albert (2015), «Mitos, sueños y realidades de El Dorado Minero» en Broder, Albert et alia (eds.), La inversión extranjera en la minería española, IGME, Madrid, pp. 71-277.

CABrera, Mercedes y Rey, Fernando del (2002), El poder de los empresarios, Taurus, Madrid.

CAmeron, Rondo (1961), France and the economic development of Europe, 1800-1914, Routledge, Londres.

CARR, David (1986), Time, narrative, and history, Indiana University Press, Bloomington.

CArreras, Albert (2005), «Industria» en CARreras, Albert y TAFunEll, Xavier (eds.), Estadísticas históricas de España. Siglos XIX y XX, Fundación BBVA, Bilbao, pp. 357453.

CASson, Mark (1999), «The economics of the family firm», Scandinavian Economic History Review, XLVII (1): 10-23.

- (2010), Entrepreneurship. Theory, networks, history, Edward Elgar, Northampton.

Chastagnaret, Gerard (2000), L’Espagne, puissance miniére dans l'Europe du siécle XIX, Casa de Velázquez, Madrid. 
- (2002), «Mines et dynamiques de district dans l'Espagne du XIX ${ }^{\mathrm{e}}$ siècle» en ECK, Jean F. y LeSCuRE, Michel (dirs.), Villes et districts industriels en Europe Occidentale (XVIIe-XIXe siècle), Presses Universitaires François Rabelais, Tours.

- (2017), Des fumées et de sang. Pollution minière et massacre de masse. Andalousie, XIX siècle, Casa de Velázquez, Madrid.

Checkland, Sidney G. (1967), The mines of Tharsis, Roman, French and English enterprise in Spain, George Allen \& Unwid Ltd, Londres.

Delgado, Aquilino et alia (2011), «Minería de hierro en Riotinto (Huelva)», Boletín Geológico y Minero, 122 (3): 311-324.

Delgado, Vicente (2014), La Cámara de Industria, Comercio y Navegación de Ayamonte. Apuntes para una historia (1906-1936), Cámara de Comercio, Industria y Navegación, Ayamonte.

DíAz, Mari P. (2010), «La prensa escrita en la Sierra de Huelva» en Actas de las XXIII Jornadas del Patrimonio de la Comarca de la Sierra, Diputación Provincial, Huelva, pp. $425-452$.

DíAz, Pablo (2013), «La sucesión de las empresas familiares británicas y españolas en los siglos XIX y XX. El papel del mérito, la formación y el aprendizaje», en FERNÁNDEZ, Paloma (ed.), La profesionalización de las empresas familiares, Lid, Madrid, pp. 17-33.

Escudero, Antonio (1996), «Pesimistas y optimistas ante el boom minero», Revista de Historia Industrial, 10: 69-91.

FernÁndez, Francisco J. y Gutiérrez, Fernando (2017), «What is a family business?», Journal of Evolutionary Studies in Business, 2 (2): 1-15.

FernÁndez, Francisco J.; Lopez, Jesús D. y Gutierrez, Fernando (2014). «Family cohesion as a longevity factor of business with intergenerational transmission». Enterprise \& Society, 15 (4): 791-819.

FERnÁndez, Paloma (ed.) (2013), La profesionalización de las empresas familiares, Lid, Madrid, pp. 17-34.

Fernández, Paloma y Puig, Nuria (2004), «Knowledge and training in family firms of the European periphery: Spain, 18th to 20th centuries», Business History, 46 (1): 79-100.

- (2007), «Bonsais in a wild forest? A historical interpretation of the longevity of large Spanish family firms», Revista de Historia Económica, XXv (3): 459-498.

Fernández, Rocío (2006), Paseo literario por Moguer, el Puerto de Santa María y Sevilla de la mano de Juan Ramón Jiménez. Disponible en línea: http://www.juanramon-zenobia.com/descargas/paseo_literario.pdf.

Ferrero, María D. (2000), Un modelo de minería contemporánea. Huelva: del colonialismo a la mundialización, Universidad de Huelva, Huelva.

Flores, Manuel (2017). Los Rothschild y la venta de las minas de Río Tinto en el proceso de la Ley General de Desamortización de Madoz, Universidad de Huelva, Huelva.

Fourneau, Francis (1978), El impacto del polo de desarrollo en la provincia de Huelva (1964-1974), Instituto de Desarrollo Regional, Sevilla. 
Frydman, Roman y Phelps, Edmund (2013), Rethinking expectations: the way forward for macroeconomics, Princeton University Press, Princeton.

Gallo, Miguel A. (1998), La sucesión en la empresa familiar, Servicio de Estudios La Caixa, Barcelona.

GARrido, Patricia y PÉREZ, Juan D. (2016), «La primera campaña mediática sobre contaminación en España» en Guimaraes, Paulo y Pérez, Juan D. (eds.), Conflitos Ambientais na Indústria Mineira e Metalúrgica: Passado e Presente, CEICP-CETEM, Evora - Rio de Janeiro, pp. 269-290.

Garrues, Jósean; Hernandez, Salvador y Martn, Manuel (2002), «Capítulo 12. Actividad mercantil», en Martin, Manuel; PARejo, Antonio y Zambrana, Francisco (dirs.), Estadísticas del siglo XX en Andalucía, Instituto de Estadística de Andalucía, Sevilla, pp. 809-836.

GARRUÉS, Joseán y Rubio, Juan A. (2013), «Empresarialidad y redes empresariales», en SÁnchez, Andrés (coord.), Industrialización y desarrollo económico en Andalucía. Un balance y nuevas aportaciones, Centro de Estudios Andaluces, Sevilla.

Garrués, Jósean; Rubio, Juan A.; Hernández, Salvador (2013). «Empresarios y redes empresariales en la Andalucía contemporánea». Revista de Historia Industrial, 51 107-140.

Gómez, Manuel (1873), Guía de Sevilla y su Provincia, Imprenta de la Andalucía, Sevilla.

Gómez-Alba, Julio (2007), La cuenca carbonífera de Surroca-Ogassa, Ayuntamiento de Barcelona, Barcelona.

GONZALO Y TARIN, Joaquín (1888), Descripción física, geológica y minera de la provincia de Huelva, Imprenta de Manuel Tello, Madrid.

GrANOVETTER, Mark (1992), «Economic institutions as social constructions: a framework for analysis», Acta Sociológica, 35: 3-11.

Hagemann, Harald (2015), «Capitalist development, innovations, business cycles, and unemployment: Joseph Alois Schumpeter and Emil Hans Lederer», Journal of Evolutionary Economics, 25 (1): 117-131.

HARveY, Charles (1979), «Business history and the problem of entrepreurship: the case of the Rio Tinto Company, 1873-1939», Business History, XXI (1): 3-22.

- (1981), The Río Tinto Company: an economic history of a leading mining concern: 1873-1954, Alison Hodge, Cornwall.

LANDES, David (2006), Dinastías. Fortunas y desdichas de las grandes familias de negocios, Crítica, Barcelona.

LudwIG, Jan (2012), «Ore mining in the Sauerland district in Germany: Development of industrial mining in a rural setting», en UeKoetTer, Frank (ed.), Mining in Central Europe. Perspectives from the environmental history, Rachel Carson Center, Múnich.

MADRID, Rufino (2007), Vencer la noche: la Sevilla iluminada. Historia del alumbrado público de Sevilla, Universidad de Sevilla, Sevilla.

Mainier, José C. (2003), «Prólogo» en Delmiro, Benigno, Literatura y minas en la España de los siglos XIX y XX, Trea, Oviedo, pp. 11-13. 
Martín, Manuel; Garrues, Joseán; Hernández, Salvador (1999), «Formación de capital en Andalucía 1886-1959», Boletín Económico de Andalucía, 25: 339-357.

Miró, Lourdes (1994), Sociedades mercantiles de Huelva, 1886-1936, Diputación Provincial de Huelva, Huelva.

Mojarro, Ana (2007), La historia del Puerto de Huelva (1873-1930), tesis doctoral, Universidad de Huelva.

MOKYR, Joel (2010), «Entrepreneurship and the industrial revolution in Britain», en LANDES, David; Mokyr, Joel y BAumol, William J. (eds.), The invention of enterprise, Princeton University Press, Princeton-Oxford, pp. 183-210.

NADAL, Jordi (1984), «Los dos abortos de la revolución industrial en Andalucía», en DoMínguez, Antonio (dir.), Historia de Andalucía. La Andalucía liberal (1778-1868), Cupsa-Planeta, Barcelona, pp. 53-83.

PArejo, Antonio (1995), «Un índice anual de la producción industrial de Andalucía, (1830-1913)», Revista de Historia Industrial, 8: 11-42.

- (2005), Estadísticas históricas sobre el sector industrial, minero y energético en Andalucía. Siglo XX, Instituto de Estadística de Andalucía, Sevilla.

- (2006), «De la región a la ciudad. Hacia un nuevo enfoque de la historia industrial española contemporánea», Revista de Historia Industrial, 30: 53-101.

- (2011), «Introducción» en PAREJO, Antonio (coord.), Grandes empresarios andaluces, Lid, Madrid, pp. 11-23.

PARejo, Antonio et alia (2002), «Capítulo 7. Agricultura y pesca», en Martin, Manuel; Parejo, Antonio y Zambrana, Francisco (dirs.), Estadísticas del siglo XX en Andalucía, Instituto de Estadística de Andalucía, Sevilla, pp. 275-474.

PeÑA, María A. (1993), «Caciquismo y poder empresarial: el papel político de las compañías mineras en la provincia de Huelva (1898-1923)», Trocadero: Revista de Historia Moderna y Contemporánea, 5: 299-324.

- (1995), La provincia de Huelva en los siglos XIX y XX, Diputación Provincial de Huelva, Huelva.

PÉrez, Juan D. (2011), «Manuel Vázquez López», «Guillermo Sundheim y Giese», «Francisco Jiménez y Jiménez», «Matías López Oller», «Thomas Morrison Smith», «Bruno Wetzig Toepel», «Antonio de Mora Claros», «José Tejero y González-Vizcaíno», en PARejo, Antonio (ed.), Grandes empresarios andaluces, Lid, Madrid, pp. 248-253, 302-307, 319-324, 325-329, 341-347, 370-374, 489-493, 507-511.

- (2015), «Huelva, una ciudad insalubre. Historia de la "Bilbao del Sur"», Andalucía en la historia, 77: 14-17.

PÉrez, Manuel (1932), Pro Huelva-Extremadura, Imprenta Antonio Plata, Huelva.

PÉrez, Miguel A. y SÁnchez, Alejandro (2015), «El capital extranjero en el desarrollo de la minería española del siglo XIX», en BRODER, Albert et alia (eds.), La inversión extranjera en la minería española, IGME, Madrid, pp. 7-69.

Pinedo, Isidro (1963), Piritas de Huelva: su historia, minería y aprovechamiento, Summa, Madrid. 
Ramírez, Manuel (2002), El Ferrocarril del Vino del Condado, Asociación de Amigos del Ferrocarril, Huelva.

RIEKEN, Jorge (1857), Observaciones acerca de la importancia de las antiguas minas de cobre en el mediodía de España y Portugal, Imprenta de M. Rivadeneyra, Madrid.

- (1860), La desamortización de las Minas de Riotinto, Imprenta de D. José Reyes y Moreno, Huelva.

Ríos, Segundo (2002), «La industrialización de la pesca en Andalucía», Revista de Historia Industrial, 28: 45-67.

Rubio, José A. (2014), Andalucía durante la Segunda Revolución Tecnológica: ciclos de inversión, sociedades mercantiles y grupos empresariales, tesis doctoral, Universidad de Granada.

Rubio, José A. y GARruÉs, Jósean (2017a), «Escasez de vínculos débiles: el atraso económico de la Andalucía contemporánea desde la perspectiva de redes empresariales», Hispania, 77 (257): 793-826.

- (2017b), «Sistemas empresariales locales y territorios de progreso en Andalucía, 18861959», Revista de Historia Industrial, 68: 81-116.

SÁiz, Patricio (1999), «Patentes, cambio técnico e industrialización en la España del siglo XIX», Revista de Historia Económica, 17: 265-302.

SÁNCHEZ, Andrés (2011), «Los intereses extranjeros en las minerías andaluzas» en GALÁN, Agustín (ed.), La presencia inglesa en Huelva: entre la seducción y el abandono, UNIA, Huelva, pp. 41-69.

SAz, Silvia del (1996), Cámaras Oficiales y Cámaras de Comercio, Marcial Pons, Madrid.

SHAne, Scott (2003), A general theory of entrepreneurship: The individual-opportunity nexus, Edward Elgar, Chentelham.

SuÁrez, Miguel (2003), «Economía e instituciones en Canarias: la Cámara de Comercio, Industria y Navegación de Las Palmas», Anuario de Estudios Atlánticos, 49: 509-533.

Tortella, Gabriel y Quiroga, Gloria (eds.) (2013), Entrepreneur and growth: An international historical perspective, Palgrave-Macmillan. Basingstoke - Nueva York, pp. 219224.

VAldAliso, José M. y LóPez, Santiago (2007), Historia económica de la empresa, Crítica, Barcelona.

Veciana, José M. (1999), "Creación de empresas como programa de investigación científica», Revista Europea de Dirección y Economía de la Empresa, 8 (3): 11-36.

WADHWANI, Rohit D. y LUBISNKY, Christina (2017), «Reinventing entrepreneurial history», Business History Review, 91: 767-799. 


\title{
The myth of the California of copper: the impact of the mining boom on the Huelva business fabric
}

\begin{abstract}
In the mid 19th century, a select group of entrepreneurs attracted by the "mining boom", with ties to European and Spanish trade networks, settled in the city of Huelva. This paper addresses the evolution in the long run of this business network, which was responsible for the take-off of industrialization in the province, and the complex relations between entrepreneur, firm and the environment from an integrated point of view. First, 10 family firms spanning over two periods, separated by World War I, are analysed. After that, the institutional network which supported these entrepreneurs is studied. In the last section, in view of the relevance of the mining sector in the local economy, and within a provincial scale, some reflections are presented on the dynamic relations between availability of natural resources, institutional framework and the business network.
\end{abstract}

KEYWORDS: mining, copper, Spain, Huelva, business structure

JEL CODES: N83, N84, N93, N94

\section{El mito de la California del cobre: el impacto del boom minero en el tejido empresarial onubense}

\section{RESUMEN}

A mediados del siglo XIX un selecto grupo de empresarios, conectados con las grandes redes comerciales españolas y europeas, se establecieron en la ciudad de Huelva atraídos por el «boom minero». Este artículo aborda la evolución a largo plazo de esta clase empresarial, responsable de la activación del proceso de industrialización provincial, y las complejas relaciones entre el empresario, la empresa y su entorno desde una perspectiva integradora. En ese sentido, primero se van a analizar diez empresas familiares en dos periodos, separados por la Primera Guerra Mundial. A continuación, se estudia la red institucional en la que se apoyan estos empresarios. En el último epígrafe, habida cuenta de la importancia del sector minero en la economía local, se realizan una serie de reflexiones sobre las dinámicas relaciones entre disponibilidad de recursos naturales, organización institucional y tejido empresarial a escala provincial.

PAlabras ClaVe: minería, cobre, España, Huelva, estructura de negocio

Códigos JEL: N83, N84, N93, N94 